\title{
Optimisation of Casting Geometries for A356 Alloy Composites Reinforced with Organic Materials using Box-Behnken Design Methodology
}

\author{
Stephen Chidera Nwafor, Sunday Ayoola Oke*, Chris Abiodun Ayanladun \\ Department of Mechanical Engineering, University of Lagos, Lagos, Nigeria
}

\begin{abstract}
In an earlier article, the central composite design was applied to the determination of geometrical features of casts in a two-phase transformation process to produce the wheel covers of automobiles whereby the A356 alloy was reinforced with organic substances for composite property enhancement. This article reexamines the assumptions in that circumstance to revise and expand the optimisation through the response surface methodology to a new method, Box-Behnken design (BBD), to facilitate a comprehensive treatment of the sand casting product parameters. Casting geometrical optimisation can be modelled to involve lengths, breadths, widths, heights, densities of casts and weight loss, varied at three discrete levels. The parameters are translated into codes $(-1,0,1)$ with specified actual, minimum and maximum values. The framework, validated by published literature data, indicates its feasibility in a real-life circumstance. This article assesses the effects of the casting geometry parameters on the responses. Besides, it examines the accuracy of the parameters to predict in the regression models deployed. It is concluded that the BBD and the regression models are adequate and can predict correctly. The BBD can be applied by composite developers to improve casting dimensional accuracy and economics.
\end{abstract}

Keywords: Multivariate, Casting, Optimisation, Developing Country, A356, ANOVA

\section{Introduction}

\subsection{General}

The casting geometry idea in sand casting refers to the practice of creating measurements in sizes, shapes and the comparative positions of product features in the material, for new components or enhancing an existing component [1-6]. However, the optimal values of casting product geometries are desirable to attain a superior design when compared along classified attributes, including longevity, strength, utilisation, reliability and efficiency during the cast product usage [3,4,7-9]. Undoubtedly, right now, studies on a sand casting geometric determination of A356 alloy composites have paid little attention to optimality $[5,6]$. This is particularly striking and disturbing given the wide array of A356

\footnotetext{
* Corresponding author. Tel.: +234-8058179170

E-mail address: sa_oke@yahoo.com

Manuscript History:

Received 1 July, 2020, Revised 9 July, 2020, Accepted 12 August, 2020, Published 30 October, 2020
}

e-ISSN: $2289-7771$

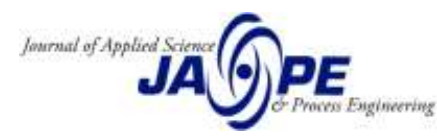


alloy composite; applications which include flywheel casting, blowers, truck chassis parts, impellers, oil pans, frame parts, auto transmission cases, machine parts and pump bodies [10].

Interestingly, the Box-Behnken design appears as an ideal candidate to fill this research gap [8, 11]. Box-Behnken designs refer to a group of rotatable or almost rotatable second-order response surface methodology design founded on three-level partially-complete factorial designs, typically used for multivariate optimisation [11]. However, it offers outstanding advantages over the centroid design for three factors; it shows significant interactions, demands a handful amount of runs and provides complete information for second-order models. Consequently, the optimisation of casting geometries of A356 alloy composite is essential for the classified attributes mentioned earlier to be attained. Moreover, casting geometrical optimisation should be widespread as a yardstick which may highlight a superior basis for scientific examination.

Right now, in foundry practice, the worker adopts an extensive array of activities to produce the A356 alloy composites, which require pouring of molten A356 alloy composite, sand making, moulding and melting. The foundry worker examines the pouring of molten A356 alloy with reinforcement into the mould, cautiously trails the temperature of the melting A356 alloy, and ensures water and fuel circulation in the casting process. In all these activities, the foundry worker lacks adequate optimal casting geometry information on the product. Unfortunately, the magnitude of this problem is expected to expand in the coming years due to an expected increase in casting activities. This research gap motivated the present researchers to optimise the casting geometries of A356 alloy assisted with organic reinforcements using the Box-Behnken design, which is noted for its outstanding application success in previous studies within the engineering domain.

Consequently, the purpose of this article is to develop a response surface methodology using the Box-Behnken design to optimise the process parameters of the cast product. A two-phase transition of the casting, involving the development of products in canoe-shaped and cuboid-shaped casts was embarked upon. This article is a response to re-examine the assumptions made to use the central composite design and to revise and expand the optimisation through the surface response methodology, to a new method, Box-Behnken approach, to facilitate a comprehensive treatment of the sand casting product parameters. The data was taken from the literature reported earlier by Nwafor et al. [12, 42]. The value brought by the use of the Box-Behnken design into the analysis is the ability to study the joint effects of the parameters at three levels with full comprehension.

From the foregoing, this research may be understood as an innovative intervention to foundry practice and research. Previously, the complex but important foundry practice where cast configurations of products should be optimised has been ignored in research but left to the judgement of the foundry worker. However, the article innovatively introduces the Box-Behnken design to optimise the casting product geometries and changes the status quo by swapping the intuitive practice of the foundry worker with the distinctive method of Box-Behnken design in response surface methodology for casting optimisation. The result of this research will be useful to foundry workers as it transmits an understanding of how to establish the product configuration of casts before the sand casting process. The implication is an enhancement in planning work for the foundry worker and an introduction to the economics of casting.

\subsection{Research problem}

Though geometries of sand casting products are expected to be accurate, according to the specifications given by the customer, this is not always the case. Design errors, material defects, errors in moulds and human error at pouring the molten A356 alloy and organic reinforcements into the mould contribute to the inaccuracies of the cast products. This is particularly needed for wheel covers used in automobiles that offer protection to wheels. Therefore, an urgent need arises to reduce these errors and 
improve the accuracies of the cast products. Furthermore, the experience of the metal fabricator is an important factor in minimising the errors of the end products. The scientific approach with the use of optimisation tools has an edge over experience as it reveals the expected dimensions to minimise errors. Therefore, it is necessary to ascertain the optimal cast product features for use during the casting process. The article aims to address this problem.

\section{Literature review}

Response surface methodology is a widespread tool to assist optimization in the areas of applied science and process engineering [13-27]. The use of RSM is somewhat wide-ranging because of the numerous benefits it possesses which outweigh the traditional techniques: the requirement for fewer experiments to examine the influences of all the factors, as well as the best grouping of all the variables, may be exposed.

While the idea of reinforcing A356 alloy with organic compounds is known already in the literature, what remains in dispute is a satisfactory scientific explanation on how to optimise a selected group of reinforcements, notably the powdered pineapple stalk, abori wood and Delonix regia, which is combined with the A356 alloy in composite development endeavour using the Box-Behnken approach. Therefore, to understand the present status of knowledge on the subject, information was drawn from the A356 alloy composite that has used the cow horn particulate, powdered rice husk ash, particulate melon shell ash and the combined powdered pineapple stalk, abori wood and Delonix regia as reinforcements. Other reinforcements used in the development of the A356 alloy composites that will be reviewed include palm kernel ash, bagasse ash and locust bean ash. In this article, the associated previous reports are explored for research gaps and observations. In the review that follows, the advantages of A356 composites that position it as attractive are explored. Then four distinct organicbased A356 alloy composites that have been reported in the literature are described (A356 reinforced with powdered pineapple stalk, abori wood and Delonix regia). The details associated with each of these are hereby explained.

\subsection{Cow horn assisted A356 alloy composite}

In recent times, the use of cow horn as reinforcements to A356 alloy has been introduced by researchers. Accordingly, Ochieze et al. [28] employed the Taguchi scheme to analyse wear experimental data produced from samples created from a spark plasma sintering process for the A356 alloy reinforced with cow horn particulates. The key finding is that the composite displayed superior dry sliding wear confrontation that exceeds the performance of the unreinforced alloy. Furthermore, the overall observation was that substantial enhancement in wear confrontational behaviour of the composite emerged. There are certainly some problems with Ochieze's et al.'s [28] work - the analysis based on Taguchi has been criticized to produce results that sometimes deviate from global optimal [29]. In the case of A356/cow horn composite, the introduction of models that capture the multiple responses of the casting problem with optimisation viewpoint, using techniques such as MOORA and grey relational analysis may correct this shortcoming. Furthermore, Ochieze et al. [30] also employed the spark plasma sintering process to appraise the microstructures and engineering properties of A356/cow horn composite. The goal was to establish an association between the parameters that control the sintering process, including the holding time, heating rate, temperature and pressure. Coupled with this, the characteristics (parameters) of the product (A356 cow horn composite) was also analysed from 
the viewpoints of compressive strength, percentage of densification, hardness, porosity and density. The key findings are that densification decayed by $3.90 \%$ at 0 to $25 \%$ of the particulate reinforcement. Nonetheless, the decline in densification is understandable as more metals are displaced by organic substances, the density reduces. Furthermore, it was found that the A356 cow horn composite revealed superior hardness measures and compressive strength weighed against the A356 alloy. The principal focus of the approach excludes optimisation. Yet optimisation may yield better results.

Nwobi-Okoye and Ochieze [17] defined a mathematical approach to solve the optimisation problem involving the production of A356 alloy reinforced with cow horn particulate. The methods of response surface evaluation and artificial neural network were deployed to solve the optimisation problem. Further efforts were made to unite simulated annealing with the neural network for a comprehensive analysis of the optimisation problem. The key findings are the feasibility of having acceptable results from the artificial neural network mathematics in the system where age hardening was experimented upon. The correlation coefficient obtained from the ANN predictions were more satisfactory than that obtained from the response surface methodology. The coupled simulation annealing and neural network system displayed results close to the experimental outcomes. However, the study has taken a unique approach by analyzing the parameters in the A356 alloy composite area where not so much modelling articles have been contributed. Nonetheless, there is an opportunity to introduce the importance rating principle in evaluation to enhance outcomes, and multi-criteria selection of parameters which may be a relevant issue.

The pioneering modelling approach of the optimisation scheme for A356/cow horn composite in Nwobi-Okoye and Ochieze [17] was taken advantage of in another publication reported in 2019. In the article, Nwobi-Okoye et al. [31] deployed multiple objective optimisation schemes in the form of artificial neural network (ANN) and adaptive neuro-fuzzy inference system (ANFIS) to predict the agehardening outcomes. When the predictions were compared with the actual results, a correlation index of 0.9985 was obtained for ANFIS, which demonstrated a more robust prediction of hardness than ANN (with a correlation index of 0.9926). However, overall, it was declared that ANN displayed superior performance to ANFIS in predicting the process values during the age-hardening circumstance of A356/cow horn composites. Though the results displayed by Nwobi-Okoye et al. [31] marked the ANFIS model as inferior to ANN in the A356/cow horn composite analysis situation, the under evaluation of the performance may be because the fuzzy theory has been included in the ANFIS model and has been under-evaluated. The fuzzy theory accounts for uncertainty but this was not captured in the ANN model. This prompts further investigation on the use of fuzzy logic model alone for tests in future studies. Certainly, there is sufficient scope for research in this area, which

- deals with robust optimisation models such as the ant colony optimisation

- looks particularly at the introduction of binding substances to act when at least two reinforcements are used such as cow horn particulate and rice husk ash where one is regarded as the reinforcement and the other is known as the filler

- involves cow horn and $\mathrm{Al}_{2} \mathrm{O}_{3}$ introduced as reinforcements in $\mathrm{A} 356$ alloy for composite development

- aims at describing and explaining the possible microstructural changes that may exist when A356 alloy is used with cow horn particulates in a hot extrusion process.

In conclusion, the sliding behaviour, sintering process parameters, physical and mechanical characteristics of the A356/cow horn composites have been related to the reinforcement weight percentages and the process responses. Together with predictive and optimisation models, they show potentials of cow horn assisted A356 composites and details have been presented in this section. The 
A356/cow horn composites' characteristics were compared with diverse parameters to establish which parameter offers the most promising results.

\subsection{Rice husk ash assisted A356 alloy composite}

Rice husk ash is an industrial waste with much significant value in the composite industry. As waste researchers thought that the value has not been fully proven for A356 composite development, an increasing effort has been made by more researchers in the area. Consequently, Subrahmanyam et al. [32] examined the impact of rice husk ash (RHA) on A356.2 alloy at 2, 4 and $8 \mathrm{wt} \%$ by volume of the reinforcement. The focus was to analyse the mechanical properties, which were hardness, tensile, impact and percentage elongation. The key finding was that the mechanical characteristics of the composite responded to an increasing growth following additions of the reinforcement, but an extra-ordinary performance was demonstrated by the $8 \mathrm{wt} \%$ RHA. A uniform distribution of the reinforcement was noticed within the A356.2 matrix. The problem with the work by Subrahmanyam et al. [32] was that the experiments were not based on an extended range of reinforcement weight $\%$ by volume, for instance; and extending it to $20 \mathrm{wt} \%$ of reinforcement in steps of $2 \mathrm{wt} \%$ may have revealed more understanding since many research have often taken the upper boundary reinforcement weight (i.e. $8 \mathrm{wt} \%$ as the superior grade in terms of enhanced mechanical property display.

Prasad and Ramakrishna [33] developed the A356.2 alloy/rice husk ash composite using the unique method of the vortex. The focus was to analyse the three properties of the composite, including hardness, ultimate strength and density. Based on the key findings, the authors reported that at the vicinity of the RHA particulate, greater values of hardness was experienced. It was concluded that the RHA powder reduced the composite's density values but enhanced some mechanical characteristics of the composite. From a different viewpoint, Prasad and Ramakrishna [34] have emphasized the importance of wear for A356/RHA composite to bridge the gap to introduce new industrial practices. While the vortex method was argued as effective for the fabrication process, they declared that composites displayed elevated hardness and confrontation to wear when weighted against unreinforced A356 alloy. But given the understanding that the vortex method is an advancement of the stir casting method, a cost-benefit ratio of the two methods of fabrication may enhance the understanding of the community members' choice of either technique.

Vinod et al. [35] developed an A356 alloy composite that hybridized RHA and fly ash. Although the stir casting method that has been associated with A356 alloy/organic composites since the early report of Prasad and Krishna [34], a more advanced version involving a double aspect was used in the work. The key finding was that substantial enhancement in the values of porosity, hardness and density were observed as the reinforced hybrid RHA and fly ash was added to the A356 alloy. However, the authors improved on the choice of reinforcement weight ratio from 2, 4 and $8 \mathrm{wt} \%$ often used in literature to five-point experimentation trials of $0,5,7.5,10$ and $12.5 \mathrm{wt} \%$ of the RHA and fly ash. Furthermore, it is unclear what criterion the author has used to apportion values to the RHA and fly ash. Was it on an equal allotment basis and why? Furthermore, the authors could have brought knowledge from the fabrication of earlier A356 alloy/RHA composite alone or A356 alloy/fly ash to judge the possible content of reinforcement that would give the utmost enhancement of the composite. Furthermore, the percentage densification that was taken as a property in previous studies was ignored and it is not understood why the omission was made. Another study on RHA reinforced A356.2 alloy was developed by Haque et al. [36]. Haque et al. [36] fabricated the A356.2/RHA composite to determine the mechanical characteristics of the composite; the stir casting method was the route of fabrication of the composite. The hardness of the composite reduced as a growth of the wt $\%$ reinforced RHA was noticed. Another key finding is that ductility of the composite increased as the wt $\%$ of reinforcement was affected. The work incorporates the novel aspect of analysing ductility of the 
composite; to the best of the authors' knowledge, there is the complete omission of this property evaluation in the literature. Nevertheless, scholars still need to expand the scope of the wt $\%$ for the reinforcement tested. The emergence of the work validates route to production as effective but also raises issues about the possible integration of reinforcement such as cow horn particulate with the rice husk ash and the A356 alloy formed may be very interesting to analyse.

\subsection{Melon shell ash assisted A356 alloy composite}

Abdulwahab et al. [37] showed a distinction in approach by adopting the melon shell as powder ash reinforcement to A356 alloy. The wear characteristics of the products were pursued under two separate loads of 2 and $5 \mathrm{~N}$, which accompanied the dry sliding experiments. .

One key result of Abdulwahab et al.'s [37] study is that the fabricated composite revealed less wear rate amounting to $2.182 \times 10^{-4} \mathrm{~mm}^{3} / \mathrm{Nm}$ at $20 \mathrm{wt} \%$ melon shell ash powder subjected to $5 \mathrm{~N}$ load. Furthermore, a decline in wear rate with growth in wt $\%$ of melon shell ash was noticed, which suggests that wear confrontation of the A356 composite enhanced substantially with growth in percentage reinforcements. Another key result is the presence of plastic deformation of the matrix stage as revealed in the report on a microstructural examination of the A356 composite. While the emphasis on the microstructural results offers valuable incentive to foster research into A356 composite development, it is also significant to think of a methodology to translate microstructural information into quantitative reasoning such that the user may not need to carry out experiments all the time for the same product inputs but with slight changes in some parameters. Research is needed to fulfil this need.

\subsection{Palm kernel assisted A356 alloy composites}

Aigbodion and Ezema [38] employed the ash produced from palm kernel nanocomposite to reinforce the A356 alloy, which is the heavier component of the composite. Based on the unique method of double gradation feeding scheme of the stir casting method, a weight $\%$ addition of $1 \mathrm{wt} \%-4 \mathrm{wt} \%$ of the nanoparticle ash, the density, mechanical properties, microstructure and electrical properties of the composite were analysed. The key finding is that enhancement in the yield strength, hardness quantities, percentage elongation, tensile and impact energy of the nanoparticle waste at $4 \mathrm{w} \%$ was achieved. Though the work provides a standpoint for future studies, and additional properties that deviate from previous literature (yield strength and percentage elongation) have been studied, it is surprising to still observe the non-participation of scholars in the research endeavour to uncover details of specific modulus, thermal expansion, strain, tear and thermal conductivity of the composite; these important details are still missing in the current work and the literature at large.

Recently, the research group of Ezema and Aigbodion [39] added a contribution that substantially determined the electrochemical accomplishment of A356 alloy/palm kernel ash nanopowder composite. With an initiative to improve on the earlier work by Aigbodion and Ezema [38] through extending the weight $\%$ of the reinforced composite, and a new path of the electrochemical property determination opened up which was a unique contribution. However, gaps still exist on the physical properties of tear, thermal conductivity and strain as pointed out in the earlier paper as a deficiency of the work.

\subsection{Bagasse ash assisted A356 alloy composite}

A unique contribution on tapping the potentials of bagasse ash as reinforcement to A356 alloy was made by Satishkumar et al. [40]. The wide range of reinforcement weight percentage addition to the matrix was extended from $8 \mathrm{wt} \%$ that is usually observed in the rice husk ask reinforced A356 alloy composite, for instance, to a maximum of $10 \mathrm{wt} \%$. The density, mechanical characteristics and 
microstructure of the A356/bagasse composite was analysed. The key finding was an enhancement in compressive strength, tensile strength, hardness and a decline in the impact strength along with the increased additional reinforcement to the matrix. However, scholars need to revisit the hybridization of reinforcements and transfer the idea to the A356 alloy/bagasse composite domain as the knowledge gap is wide open for research and practice activities.

\subsection{Locust bean ash assisted A356 alloy composite}

Locust bean ash composites are scarce in the literature and the effort of Usman et al. [41] to introduce this to the A356 alloy/locust bean ash domain is very promising. The method of production applied in the study is the traditional stir casting procedure. A comprehensive analysis integrating wear property evaluation with mechanical properties was successfully pursued. The key finding of the study is that an elevated impact of reinforcement addition was experienced regarding the mechanical properties. A significant decline in the wear rate was also reported as the weight ratio of the powder locust bean as A356 alloy composite increased. The study is consistent with most reports that chose the terminal values of the reinforcing wt $\%$ as promising for improved hardness, wear-resistance and tensile strength. However, a question arises which is "should the limit of wt $\%$ reinforcement addition be $12.5 \mathrm{wt} \%$ as observed in previous literature?" Another question is "what restrains authors from further investigations to increase this to say $35 \mathrm{wt} \%$ reinforced locust bean ash A356 composite and carry out property tests at such mixture levels?"

Most research involving organic-assisted A356 alloy matrix sought to establish the characteristics of the developed composites with limited reinforcement types used in previous studies: cow horn particulate, powdered rice husk as, particulate melon shell ash and the combined powdered pineapple stalk, abori wood and Delonix regia. The established characteristics were in the directions of microstructural analysis, mechanical property evaluation and tribological analysis. Furthermore, a few optimisation tools have been used such as the artificial neural network, adaptive neuro-fuzzy inference system and central composite design based on response surface methodology. Besides, casting geometry seems to be established in general but there is no such study reported on A356 composite. It may, therefore, be beneficial to also study the casting geometry of A356 with combined powdered pineapple stalk, abori wood and Delonix regia using the Box-Behnken response surface methodology. This need is pressing as the proposed approach has high practical prospects and validity. But, few articles have used the Box-Behnken approach in composite development and none has applied it to the problem of casting geometric analysis using the combined powdered pineapple stalk, abori wood and Delonix regia as reported in this article. The only article of close similarity to this work has exploited the central composite design approach. But the Box-Behnken design has tremendous advantages at three levels over the central composite design approach, which makes it compelling to apply in the present case. Therefore, additional investigations using the Box-Behnken design on this specified composite would be of assistance to better understand the casting geometry of the proposed composite.

\subsection{A356 alloy composite using combined pineapple stalk, abori wood and Delonix regia}

Only two articles have been published using the combined pineapple stalk, abori wood and Delonix regia as reinforcements. In the first article, Nwafor et al. [12], the discussion was totally at variance with the existing literature; to the best of the reviewer's knowledge, all articles that developed the A356 alloy/organic composites focused on any of the following - microstructural analysis, mechanical property assessment, electrochemical analysis and wear resistance measurements but none had earlier focused on casting geometry in sand casting. The main concern of the article was to optimise the casting geometry of the A356 alloy reinforced with three substances, pineapple stalk, abori wood and Delonix regia, using three variant models of Taguchi-Pareto, Taguchi-ABC and the classical 
Taguchi method. By accounting for the process parameters to include weight, length, breadth, and density, the responses were defined as the total weight of the organic substance used in the melting process and the weight loss. Since two-phase of casting were defined: canoe-shaped and cuboid-shaped, the results revealed that the density parameter of the former casting shape had the greatest influence on the casting process. While the article may have taken a new direction, it is anticipated that future work may enlarge the optimisation scope. At present, the problem with the paper is the application of optimisation techniques that is limited to the Taguchi methods alone. However, it should be noted that the Taguchi method has been criticised to yield local optimum at times. If this exists, then other superior models could be tested. A useful candidate in this direction is the TOPSIS-Taguchi method, which avoids local optimal by tracking the casting geometry problem from a multiple attribute perspective.

In the second article, Nwafor et al. [42], the authors focused on the production of wheel covers similar to the application target of the previous paper, Nwafor et al. [12]. The study used the sand casting process to produce casts in two phases, the canoe-shaped and cuboid-shaped production phases. Based on the intention to optimise the casting geometry of the two mentioned configurations, the central composite design methodology was used on the process parameters, including the width of product, length, breadth and weight while the response variables were taken as the weight loss and the total weight of the organic substance engaged in the production process. It was declared that the central composite design model competently optimised the problem. While the study promotes interest in casting geometry optimisation, the gap to fully explore more of the optimisation methods is still there, including the Box-Behnken design in the response surface methodology toolkit of optimisation procedures.

\subsection{Summary of literature review}

The findings made after a brief literature review on the A356 alloy/organic composite indicates the following:

1. The production of A356 alloy/organic composites have been achieved using the following production routes - stir casting, double stir casting, spark plasma sintering and sand casting.

2. The diverse reinforcements used to produce the A356 alloy/organic composites include cow horn particle and ash, rice husk ash, melon shell ash, palm kernel ash, bagasse ash, locust bean ash and combined pineapple stalk, abori wood and Delonix regia.

3. Active publication activities commenced in the area of A356 alloy/organic composites since 2011 with a scanty number of published articles added year by year. However, the number of articles published in the last three years is unprecedented; indicating the growing interest of researchers and stakeholders in the area and it is expected to grow in the coming years.

4. Mathematical modelling has just been introduced in the area about a few years ago and increased interest has been demonstrated since its introduction in the A356 alloy/organic composites area.

5. Optimisation tools have become a key concern of mathematical modellers in the area of A356 alloy/organic composites.

6. Interest in the analysis of the casting geometry of samples had just begun and it is expected to increase in the next few years. 
Table 2. Literature review in A356 alloy/organic composite research

\begin{tabular}{|c|c|c|c|c|c|c|}
\hline Authors & Parameters used in the work & $\begin{array}{l}\text { Method of } \\
\text { production }\end{array}$ & $\begin{array}{l}\text { Organic } \\
\text { materials used }\end{array}$ & Method/tools used & Application(s) & Sample origin \\
\hline $\begin{array}{l}\text { Gowda and Prasad } \\
\text { [43] }\end{array}$ & Density, $\%$ corrosion rate & $\begin{array}{l}\text { Stir casting } \\
\text { technique }\end{array}$ & $\begin{array}{l}\text { Rice husk ash with } \\
\mathrm{Al}_{2} \mathrm{O}_{3}\end{array}$ & - & - & India \\
\hline $\begin{array}{l}\text { Subrahmanyam et } \\
\text { al. [32] }\end{array}$ & $\begin{array}{l}\text { Tensile test, \% elongation, hardness test, } \\
\text { impact test }\end{array}$ & $\begin{array}{l}\text { Portable furnace } \\
\text { used }\end{array}$ & Rice husk ash & - & $\begin{array}{l}\text { Marine and } \\
\text { aviation }\end{array}$ & India \\
\hline $\begin{array}{l}\text { Prasad and } \\
\text { Ramakrishna [33] }\end{array}$ & Density, ultimate tensile strength, hardness & Vortex method & Rice husk ash & - & $\begin{array}{l}\text { Automotive } \\
\text { components } \\
\text { (pistons, cylinder } \\
\text { liners, connecting } \\
\text { rods) }\end{array}$ & India \\
\hline $\begin{array}{l}\text { Prasad and } \\
\text { Ramakrishna [34] }\end{array}$ & Wear loss, wear rate, hardness & Vortex method & Rice husk ash & - & $\begin{array}{l}\text { Automotive } \\
\text { industry }\end{array}$ & India \\
\hline $\begin{array}{l}\text { Subrahmanyam et } \\
\text { al. [44] }\end{array}$ & $\begin{array}{l}\text { Hardness test, tensile test, elongation, } \\
\text { compression test, impact test }\end{array}$ & $\begin{array}{l}\text { Graphite crucible } \\
\text { used }\end{array}$ & $\begin{array}{l}\text { Rice husk ash with } \\
\text { fly ash }\end{array}$ & - & $\begin{array}{l}\text { Aviation and } \\
\text { automotive sectors }\end{array}$ & India \\
\hline Vinod et al. [35] & $\begin{array}{l}\text { Weight fractions of reinforcements, } \\
\text { hardness, density and porosity }\end{array}$ & $\begin{array}{l}\text { Double stir } \\
\text { Casting }\end{array}$ & $\begin{array}{l}\text { Rice husk ash } \\
\text { and fly ash }\end{array}$ & - & - & India \\
\hline $\begin{array}{l}\text { Nwobi-Okoye et al. } \\
\text { [31] }\end{array}$ & $\begin{array}{l}\text { Hardness values, temperature, ageing time, } \\
\text { cow horn particle weight } \%\end{array}$ & $\begin{array}{l}\text { Spark plasma } \\
\text { Sintering }\end{array}$ & Cow horn particles & $\begin{array}{l}\text { Artificial neural network, adaptive neuro- } \\
\text { fuzzy inference system, genetic algorithm }\end{array}$ & - & Nigeria \\
\hline Ochieze et al. [28] & $\begin{array}{l}\text { Wear rate, wear loss, applied load, sliding } \\
\text { velocity, sliding distance }\end{array}$ & $\begin{array}{l}\text { Spark plasma } \\
\text { Sintering }\end{array}$ & Cow horn particles & Taguchi method & - & $\begin{array}{l}\text { Nigeria, South } \\
\text { Africa }\end{array}$ \\
\hline Ochieze et al. [30] & $\begin{array}{l}\text { Hardness values, percentage densification, } \\
\text { compressive strength, density, porosity }\end{array}$ & $\begin{array}{l}\text { Spark plasma } \\
\text { Sintering }\end{array}$ & Cow horn ash & - & - & Nigeria \\
\hline $\begin{array}{l}\text { Nwobi-Okoye and } \\
\text { Ochieze [17] }\end{array}$ & $\begin{array}{l}\text { Hardness values, temperature, wt } \% \text { of cow } \\
\text { horn ash, time }\end{array}$ & $\begin{array}{l}\text { Spark plasma } \\
\text { Sintering }\end{array}$ & Cow horn powder & $\begin{array}{l}\text { Response surface methodology, artificial } \\
\text { neural networks, simulated annealing }\end{array}$ & Brake drum & Nigeria \\
\hline $\begin{array}{l}\text { Aigbodion and } \\
\text { Ezema [38] }\end{array}$ & $\begin{array}{l}\text { Density, electrical properties, hardness } \\
\text { values, tensile, yield strength, \%elongation, } \\
\text { impact energy }\end{array}$ & $\begin{array}{l}\text { Double layer feed } \\
\text { stir casting }\end{array}$ & $\begin{array}{l}\text { Palm kernel shell } \\
\text { ash }\end{array}$ & - & $\begin{array}{l}\text { Biomedical, } \\
\text { defense, aviation, } \\
\text { transpiration, and } \\
\text { building }\end{array}$ & Nigeria \\
\hline Nwafor et al. [12] & $\begin{array}{l}\text { Length, weight, height, width of product, } \\
\text { total weight of organic material, weight loss }\end{array}$ & Sand casting & $\begin{array}{l}\text { Pineapple sucker, } \\
\text { Delonix regia and } \\
\text { abori wood }\end{array}$ & $\begin{array}{l}\text { Taguchi-Pareto Analysis, Taguchi-ABC } \\
\text { Analysis and Taguchi methods }\end{array}$ & $\begin{array}{l}\text { Wheel covers } \\
\text { (automobiles) }\end{array}$ & Nigeria \\
\hline Nwafor et al. [42] & $\begin{array}{l}\text { Weight, height, length, width of product, } \\
\text { weight loss, total weight of organic material }\end{array}$ & Sand casting & $\begin{array}{l}\text { Delonix regia, } \\
\text { pineapple sucker } \\
\text { and abori wood }\end{array}$ & $\begin{array}{l}\text { Central composite design of response surface } \\
\text { methodology }\end{array}$ & $\begin{array}{l}\text { Wheel covers } \\
\text { (automobiles) }\end{array}$ & Nigeria \\
\hline
\end{tabular}

e-ISSN: $2289-7771$ 


\section{Materials and methods}

\subsection{Materials}

This paper emerges from Project 1.0, an initiative developed to produce wheel covers from outof-use A356 alloys. The casting work (Figure 1) was therefore carried out in a foundry located at Fola Agoro, Lagos, Nigeria, while the used engines were purchased from a shop in Bariga. The foundry shop was primarily concerned with producing aluminium metal castings. The main facilities, equipment and tools used for the sand casting equipment were the sand, mould, pattern and the furnace. The foundry sand was of first-rate equal-sized and clean nature, often used in distinct manners: for moulding, to create the exterior shape of the wheel cover that was experiencing casting, and as cores, to create the interior void spaces in the wheel cover being produced. The foundry sand was recovered as it was allowed to cool and then re-established to produce other products. The sand was made available by the foundry.

The shaped (modified) sand served as the mould since modern A356 alloy with the reinforced organic products were poured into it. It was shaped by a pattern, which was prepared by a wood designer but supplied by the foundry worker for use in the experiment. The pattern was however described as an imitation of the wheel cover, which was to be cast. The melting furnace was the traditional type that comprised the burner, steel pot, electric blower, steel cover and used oil (stored) to support the melting activities. The burner was of cylindrical hollow shape, which was laid on the ground. It was built from stone and steel components. It was connected with the used oil storage tank. The steel pot which was the recepticle for melting materials, was placed inside the burner. The used oil storage tank where the used oil was stored transported the oil to the burner through the tap on the storage and passed through a hose and funnel. The tap also controlled the movement of the oil to the burner. The used oil storage tank had a sieve on top to remove impurities from the used oil as it was being poured into it. The used oil was obtained from engines in vehicles and generators as disposed-off oil. This was obtained when the oil in the engines was due for a change. The electric burner provided air to aid in combustion. The electric blower was switched on through an electric switch. As the fan in the electric blower turned, air moved through the nozzle of the electric blower into the burner. The steel cover (wheel), which was used to cover the burner controlled the heat in the burner and prevented heat loss. The steel tong was used to place and remove the steel cover on and from the burner, used to remove the steel pot from the burner and to hold the small steel place used in removing the molten substance from the pot.

The engines used were condemned engines to be disposed of but still able to be re-melted and reused for value-adding production of wheel covers for vehicles. Three units of engine blocks were used, totalling $31 \mathrm{~kg}$ in weight, with the first, second and third units measuring $10 \mathrm{~kg}, 10 \mathrm{~kg}$ and $11 \mathrm{~kg}$, respectively. A sledgehammer was then used to break the units of engine blocks into smaller pieces that could be comfortably melted in an improvised container that could contain about 5 to 10 litres of melted A356 alloy at an instance. These broken pieces were then placed in the container and set on the furnace for melting. Concurrently, as the melting was taking place, the moulds to which the melted A356 alloy was to be poured into was being prepared using a canoe-shaped pattern of roughly $23 \mathrm{~cm}$ by $7 \mathrm{~cm}$ by 5 $\mathrm{cm}$ in length, breadth and height, respectively. The foundry sand, which is a special type of soft sand with minute particulates that stick together to avoid cracking when used to create moulds, conforming to the pattern that was applied in this study. It is black and closely resembles the humus soil commonly found in fertile agricultural lands.

\subsection{Methods}

\subsubsection{Box-Behnken design}

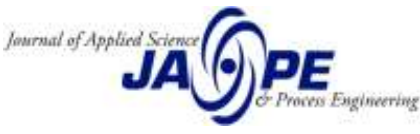


The Box-Behnken design is an optimisation method from the family of "Design of experiments' that seeks to understand the impact of casting geometry variables on the casting outcome through a regulated environment. The requirements necessary to understand the Box-Behnken design is to first establish the independent factors and then examine their impact on the response(s), often referred to as the dependent factors. To experiment with this method, the levels and factors need to be specified. Then experimental trials are conducted and each of these trials will entail the factors and levels of the casting geometry idea that is being analysed. The Box-Behnken design is a member of the response surface methodology designs that will run the casting geometry experiment competently at three levels and performance advantages to the central composite design makes the Box-Behnken design a preferred method. What makes the three-level design of Box-Behnken design outstanding is that there are no points at the vertices representing the experimental area. The value of this absence of points at the vertices may be appreciated when the points symbolize level combinations, which are extremely costly or challenging to test given the physical process limitations. Often, results from the Box-Behnken design are subjected to analysis of variance test in search for statistically significant variables and their interfaces. From previous works, the level of significance is commonly taken at $p<0.05$.

\subsubsection{The basis to use Box-Behnken design}

In this paper, the Box-Behnken design approach is pursued instead of the previously established results for the central composite design (CCD) approach. The CCD was demonstrated for its casting geometry optimization problem of the A356 alloy/organic composite by some authors. Here, it is argued that these two methods are different and a research endeavour is worthwhile to pursue the BBD as an optimization approach in the current instance. The reasons promoting the BBD are henceforth stated. The BBD is a worthwhile approach compared to the CCD because it has fewer design points; when weighed against the axial points in the $\mathrm{CCD}$, the number of experimental trials exceeds that of BBD. For instance, the CCD will require five additional experiments as opposed to BBD (i.e. 20 experiments for CCD against 15 experiments for BBD considering three factors. However, CCD has the credit of testing at extreme situations thereby better suited for quadratic functions. Second, the BBD is closer to the face-centred composite design $($ alpha $=1$ ) having fewer experiments while the CCD has an alpha equal to the square root of the number of experiments. Third, for the BBD approach, no point exists within the cubic vertex which produces the upper and lower ceiling of each variable. However, for the $\mathrm{CCD}$, each factor possesses points beyond the lowest and highest array. This implies that more number of tests is necessary for CCD compared to BBD. From the preceding argument, it is clear that the current paper differs from the previous paper by Nwafor et al. [42]. However, the current paper builds on the study and the conclusions arising from this previous work.

\subsubsection{Preparation of sand and mould}

Foundry sand is often prepared without the pattern and the mould may be built without the pattern also. At this preliminary phase of Project 1.o, which produces the data for this work, efforts were focused on the development of canoe-shaped and cuboid-shaped casts. The sand was prepared differently for each of the two casting activities according to the shape desired. First, the sand for the canoe-shaped cast was prepared before preparing the sand for casting the cuboid-shaped casts. Furthermore, the sand was poured on the ground and a part of the foundry was set apart as the work area, which after the casting, became free to use for other casting engagements. The size of the sand is often lower than the common "Shaka sand" used as building materials since it is required that no pores be present so that the sand will stick together. The sand for the canoe-shaped cast was mixed and some water was skillfully added so that as the sand was poured on the exterior of the canoe-shaped pattern and removed, there 
would not be cracks in the mould or it would not collapse in the worst case. This same procedure was followed when the pattern was changed to the cuboid-shaped casting for the second phase of the cast production. In preparing the sand, the hand was used to dress the sand, a case similar to what is done in pottery where the hand is skillfully applied to dress the final object being produced. In the sand casting situation, after putting a mass of foundry sand together and the pattern is put in-between, the hand is used to dress the exterior parts of the mould while the canoe-shaped or cuboid-shaped pattern will normally form a shape inside the mould that is similar to the body of the pattern. However, at the time, some wooden waste that tended to deform the internal surfaces of the moulds was removed when observed. If left without removal and the molten metal is poured, defect on the surface of the casting objects will be observed as the surface will not be smooth.

\subsubsection{Sand casting process}

The sand casting process is well known for its great utility and flexibility to change aluminium metal matrix composites, through intense heating and melting into melts of various shapes that get solidified as a result of cooling. The process uses foundry sand to build up moulds on the ground; after inserting the pattern into the space provided for moulding. From this, complicated metallic parts are made. The sand casting process has been proven to possess the ability to cast aluminium matrix composites with elevated melting temperatures.

Discussion of composite casting with a special interest in casting geometry will essentially drawn upon the relationship between the response and the grouping of the independent variables With foundation form, the work of Pai et al. [16], the association between the several variables has been established and repeated in Nwafor et al. [12]. Readers are directed to these sources for more details. As the Box-Behnken design is used for experimentation in this paper, the details of the factors and levels and other associated analysis are the same and readers are directed to Nwafor et al. [12, 42] for full details. However, only the factor-level table is repeated here for the ease of understanding the proposed procedure (Table 1). Similar to Nwafor et al. [42], a total of eight factors were considered for analysis in three-level arrangement with the factors named as (length of cast 1(LC1), weight of cast 1(WC1), height of cast 1(HC1), width of cast 1 (WiC1), weight of cast 2 (WC2), length of cast 2 (LC2), breadth of cast 2 (BC2), total weight of organic materials (TWOM).

Table 1. Factors and levels of A356 alloys for the problem [12, 42]

\begin{tabular}{ccccl}
\hline S/No. & $\begin{array}{l}\text { Factor } \\
\text { (parameter) }\end{array}$ & $\begin{array}{c}\text { Level } \\
1\end{array}$ & $\begin{array}{c}\text { Level } \\
2\end{array}$ & $\begin{array}{c}\text { Level } \\
3\end{array}$ \\
\hline 1 & LC1 & 0.286 & 0.282 & 0.286 \\
2 & WC1 & 1.898 & 1.826 & 1.998 \\
3 & HC1 & 0.038 & 0.036 & 0.039 \\
4 & WiC1 & 0.101 & 0.097 & 0.1 \\
5 & WC2 & 1.77 & 1.68 & 1.83 \\
6 & LC2 & 0.264 & 0.264 & 0.264 \\
7 & BC2 & 0.24 & 0.241 & 0.24 \\
8 & TWOM & 0.2847 & 0.23 & 0.1996 \\
\hline
\end{tabular}

\section{Results and discussion}


The development of sand casting samples for A356 alloy/organic composites suffers from an acute but inherent weakness; the disadvantage of not being optimised when considering the casting geometries of the samples. This is simply due to the absence of standard procedures to the foundry workers for casting tasks. Fortunately, optimisation is gradually being proved as an effective method to produce sound cast products using a growing range of optimisation schemes such as the Taguchimethod, Taguchi-Pareto analysis and Taguchi-ABC scheme as well as the central composite design of the response surface methodology. However, no application has been made of the promising BoxBehnken design. Towards solving this problem, published data is complemented with experimental details and the results presented with the discussion in the present section of the article.

\subsection{Box-Behnken design}

Box-Behnken design is adopted in this experiment; the experimental design matrix, the factors and responses of A356 alloy/organic composites for the problem is shown in Tables 2, 3 and 4, respectively, which were generated using the Minitab-16 software. Seven factors were used in the BoxBehnken design. Table 2 shows the regression analysis for the volume of cast 1 , no factor is statistically significant to the response (Volume of cast 1 ) using their $p$-values. Using the $f$-value in the ANOVA table (Table 4) we see that $\mathrm{LC} 1 * \mathrm{HC} 1, \mathrm{LC} 1 * \mathrm{TWOM}, \mathrm{HC} 1 * \mathrm{WC} 2$ and $\mathrm{WC} 2 * \mathrm{BC} 2$ all with values of 1.30 are significant. The case shows that $32.71 \%$ in light output which is the R-sq value, the model is overfitted because the R-sq(pred) value, the regression $\mathrm{f}$-value of 0.36 shows a low significance for the regression model and also shows that linear regression, square and interaction of A356 alloy model are insignificant. In Table 3, the p-value of all factors is greater than 0.05 , which makes them insignificant, but $\mathrm{LC} 1 * \mathrm{WC} 2$ with $\mathrm{f}$-value of 2.35 , WC $1 * \mathrm{WiC} 1$ with $\mathrm{f}$-value of 1.86 , while $\mathrm{LC} 1 * \mathrm{HC} 1, \mathrm{LC} 1 * \mathrm{TWOM}$, $\mathrm{HC} 1 * \mathrm{WC} 2$ and $\mathrm{WC} 2 * \mathrm{BC} 2$ with $f$-value of 1.43 are statistically significant in that order from Table 4 and the model is $38.62 \%$ in light output and overfit, the regression $\mathrm{f}$-value of 0.47 in the ANOVA table (Table 4) shows that the regression model has low significance, it also shows that the linear, square and interaction are insignificant. The regression analysis for a response (Weight loss) in Table 3, the model is $48.04 \%$ in light output and it is also overfitting, $\mathrm{WC} 1, \mathrm{WC} 2 * \mathrm{WC} 2, \mathrm{WC} 1 * \mathrm{HC} 1, \mathrm{WC} 2, \mathrm{LC} 1 * \mathrm{WC} 2$ and $\mathrm{HC} 1{ }^{*} \mathrm{HC} 1$ with $\mathrm{f}$-values of $2.64,2.01,1.82,1.80,1.79$ and 1.52 respectively are significant in that order, the linear, square and interaction in Table 3 are also insignificant. The regression model of the weight loss also has a low significance with regression $\mathrm{f}$-value of 0.69 . Residual plots for the volume of cast 1 , the density of cast and weight loss are shown in Figures 1, 2 and 3 respectively of A356 alloy. The normal probability plot is not a straight line in Figure 1- it is S-shaped. The histogram of residual and frequency plot for the volume of cast 1 , density of cast and weight loss does not have normally distributed shape. Fitted value and residuals plot show scatter distribution points in Figures 1, 2 and 3, since the scatter points made specific shape, indicating a weak model. 
Table 2. Experimental design matrix with the factors and responses of A356 alloy

\begin{tabular}{|c|c|c|c|c|c|c|c|c|c|c|c|c|c|c|c|c|c|}
\hline \multirow{2}{*}{ No } & \multicolumn{7}{|c|}{ Coded values } & \multicolumn{7}{|c|}{ Actual values } & \multicolumn{3}{|c|}{ Response } \\
\hline & $\mathrm{A}$ & $\mathrm{B}$ & $\mathrm{C}$ & $\mathrm{D}$ & $\mathrm{E}$ & $\mathrm{F}$ & $\mathrm{G}$ & LC1 & WC1 & $\mathrm{HC} 1$ & WiC1 & WC2 & $\mathrm{BC} 2$ & TWOM & $\mathrm{VC} 1$ & DC1 & WL \\
\hline 1 & 0 & + & + & 0 & 0 & + & 0 & 0.284 & 0.200 & 0.039 & 0.099 & 1.755 & 0.241 & 0.242 & 0.000446 & 4271.1 & 0.131 \\
\hline 2 & 0 & - & 0 & 0 & - & 0 & + & 0.284 & 0.183 & 0.038 & 0.099 & 1.680 & 0.241 & 0.285 & 0.000381 & 5379.9 & 0.146 \\
\hline 4 & - & 0 & + & 0 & + & 0 & 0 & 0.282 & 0.191 & 0.039 & 0.099 & 1.830 & 0.241 & 0.242 & 0.000446 & 4271.1 & 0.131 \\
\hline 5 & + & + & 0 & + & 0 & 0 & 0 & 0.286 & 0.200 & 0.038 & 0.101 & 1.755 & 0.241 & 0.242 & 0.000381 & 5379.9 & 0.146 \\
\hline 6 & + & 0 & 0 & 0 & 0 & + & - & 0.286 & 0.191 & 0.038 & 0.099 & 1.755 & 0.241 & 0.200 & 0.000471 & 4545.1 & 0.172 \\
\hline 9 & 0 & - & 0 & 0 & - & 0 & - & 0.284 & 0.183 & 0.038 & 0.099 & 1.680 & 0.241 & 0.200 & 0.000471 & 4545.1 & 0.172 \\
\hline 10 & + & - & 0 & + & 0 & 0 & 0 & 0.286 & 0.183 & 0.038 & 0.101 & 1.755 & 0.241 & 0.242 & 0.000446 & 4271.1 & 0.131 \\
\hline 11 & 0 & + & 0 & 0 & + & 0 & + & 0.284 & 0.200 & 0.038 & 0.099 & 1.830 & 0.241 & 0.285 & 0.000381 & 5379.9 & 0.146 \\
\hline 12 & 0 & 0 & 0 & - & + & - & 0 & 0.284 & 0.191 & 0.038 & 0.097 & 1.830 & 0.240 & 0.242 & 0.000471 & 4545.1 & 0.172 \\
\hline 13 & + & + & 0 & - & 0 & 0 & 0 & 0.286 & 0.200 & 0.038 & 0.097 & 1.755 & 0.241 & 0.242 & 0.000446 & 4271.1 & 0.131 \\
\hline 18 & + & 0 & 0 & 0 & 0 & - & + & 0.286 & 0.191 & 0.038 & 0.099 & 1.755 & 0.240 & 0.285 & 0.000471 & 4545.1 & 0.172 \\
\hline 19 & 0 & + & 0 & 0 & - & 0 & + & 0.284 & 0.200 & 0.038 & 0.099 & 1.680 & 0.241 & 0.285 & 0.000446 & 4271.1 & 0.131 \\
\hline 20 & - & + & 0 & + & 0 & 0 & 0 & 0.282 & 0.200 & 0.038 & 0.101 & 1.755 & 0.241 & 0.242 & 0.000381 & 5379.9 & 0.146 \\
\hline 21 & 0 & 0 & 0 & - & + & + & 0 & 0.284 & 0.191 & 0.038 & 0.097 & 1.830 & 0.241 & 0.242 & 0.000471 & 4545.1 & 0.172 \\
\hline 22 & 0 & 0 & 0 & 0 & 0 & 0 & 0 & 0.284 & 0.191 & 0.038 & 0.099 & 1.755 & 0.241 & 0.242 & 0.000446 & 4271.1 & 0.131 \\
\hline 23 & 0 & 0 & 0 & 0 & 0 & 0 & 0 & 0.284 & 0.191 & 0.038 & 0.099 & 1.755 & 0.241 & 0.242 & 0.000381 & 5379.9 & 0.146 \\
\hline 24 & - & 0 & 0 & 0 & 0 & - & + & 0.282 & 0.191 & 0.038 & 0.099 & 1.755 & 0.240 & 0.285 & 0.000471 & 4545.1 & 0.172 \\
\hline 25 & 0 & 0 & - & - & 0 & 0 & + & 0.284 & 0.191 & 0.036 & 0.097 & 1.755 & 0.241 & 0.285 & 0.000446 & 4271.1 & 0.131 \\
\hline 26 & 0 & 0 & + & + & 0 & 0 & - & 0.284 & 0.191 & 0.039 & 0.101 & 1.755 & 0.241 & 0.200 & 0.000381 & 5379.9 & 0.146 \\
\hline 27 & + & 0 & - & 0 & + & 0 & 0 & 0.286 & 0.191 & 0.036 & 0.099 & 1.830 & 0.241 & 0.242 & 0.000471 & 4545.1 & 0.172 \\
\hline 28 & 0 & 0 & 0 & + & - & - & 0 & 0.284 & 0.191 & 0.038 & 0.101 & 1.680 & 0.240 & 0.242 & 0.000446 & 4271.1 & 0.131 \\
\hline 29 & 0 & - & - & 0 & 0 & - & 0 & 0.284 & 0.183 & 0.036 & 0.099 & 1.755 & 0.240 & 0.242 & 0.000381 & 5379.9 & 0.146 \\
\hline
\end{tabular}

e-ISSN: 2289-7771 


\begin{tabular}{|c|c|c|c|c|c|c|c|c|c|c|c|c|c|c|c|c|c|}
\hline 34 & - & 0 & + & 0 & - & 0 & 0 & 0.282 & 0.191 & 0.039 & 0.099 & 1.680 & 0.241 & 0.242 & 0.000446 & 4271.1 & 0.131 \\
\hline 35 & + & 0 & 0 & 0 & 0 & + & + & 0.286 & 0.191 & 0.038 & 0.099 & 1.755 & 0.241 & 0.285 & 0.000381 & 5379.9 & 0.146 \\
\hline 36 & 0 & 0 & + & + & 0 & 0 & + & 0.284 & 0.191 & 0.039 & 0.101 & 1.755 & 0.241 & 0.285 & 0.000471 & 4545.1 & 0.172 \\
\hline 37 & 0 & - & + & 0 & 0 & - & 0 & 0.284 & 0.183 & 0.039 & 0.099 & 1.755 & 0.240 & 0.242 & 0.000446 & 4271.1 & 0.131 \\
\hline 38 & 0 & 0 & - & - & 0 & 0 & - & 0.284 & 0.191 & 0.036 & 0.097 & 1.755 & 0.241 & 0.200 & 0.000381 & 5379.9 & 0.146 \\
\hline 39 & - & - & 0 & + & 0 & 0 & 0 & 0.282 & 0.183 & 0.038 & 0.101 & 1.755 & 0.241 & 0.242 & 0.000471 & 4545.1 & 0.172 \\
\hline 40 & 0 & 0 & 0 & + & + & - & 0 & 0.284 & 0.191 & 0.038 & 0.101 & 1.830 & 0.240 & 0.242 & 0.000446 & 4271.1 & 0.131 \\
\hline 41 & 0 & 0 & 0 & + & - & + & 0 & 0.284 & 0.191 & 0.038 & 0.101 & 1.680 & 0.241 & 0.242 & 0.000381 & 5379.9 & 0.146 \\
\hline 42 & + & - & 0 & - & 0 & 0 & 0 & 0.286 & 0.183 & 0.038 & 0.097 & 1.755 & 0.241 & 0.242 & 0.000471 & 4545.1 & 0.172 \\
\hline 43 & 0 & 0 & 0 & - & - & - & 0 & 0.284 & 0.191 & 0.038 & 0.097 & 1.680 & 0.240 & 0.242 & 0.000446 & 4271.1 & 0.131 \\
\hline 44 & 0 & 0 & - & + & 0 & 0 & - & 0.284 & 0.191 & 0.036 & 0.101 & 1.755 & 0.241 & 0.200 & 0.000381 & 5379.9 & 0.146 \\
\hline 45 & 0 & - & - & 0 & 0 & + & 0 & 0.284 & 0.183 & 0.036 & 0.099 & 1.755 & 0.241 & 0.242 & 0.000471 & 4545.1 & 0.172 \\
\hline 46 & - & 0 & - & 0 & + & 0 & 0 & 0.282 & 0.191 & 0.036 & 0.099 & 1.830 & 0.241 & 0.242 & 0.000446 & 4271.1 & 0.131 \\
\hline 47 & 0 & 0 & + & - & 0 & 0 & - & 0.284 & 0.191 & 0.039 & 0.097 & 1.755 & 0.241 & 0.200 & 0.000381 & 5379.9 & 0.146 \\
\hline 48 & 0 & 0 & 0 & 0 & 0 & 0 & 0 & 0.284 & 0.191 & 0.038 & 0.099 & 1.755 & 0.241 & 0.242 & 0.000471 & 4545.1 & 0.172 \\
\hline 49 & 0 & 0 & 0 & 0 & 0 & 0 & 0 & 0.284 & 0.191 & 0.038 & 0.099 & 1.755 & 0.241 & 0.242 & 0.000446 & 4271.1 & 0.131 \\
\hline 50 & 0 & + & - & 0 & 0 & + & 0 & 0.284 & 0.200 & 0.036 & 0.099 & 1.755 & 0.241 & 0.242 & 0.000381 & 5379.9 & 0.146 \\
\hline 51 & 0 & 0 & 0 & 0 & 0 & 0 & 0 & 0.284 & 0.191 & 0.038 & 0.099 & 1.755 & 0.241 & 0.242 & 0.000471 & 4545.1 & 0.172 \\
\hline 52 & 0 & + & 0 & 0 & + & 0 & - & 0.284 & 0.200 & 0.038 & 0.099 & 1.830 & 0.241 & 0.200 & 0.000446 & 4271.1 & 0.131 \\
\hline 53 & 0 & 0 & 0 & - & - & + & 0 & 0.284 & 0.191 & 0.038 & 0.097 & 1.680 & 0.241 & 0.242 & 0.000381 & 5379.9 & 0.146 \\
\hline 54 & - & 0 & 0 & 0 & 0 & - & - & 0.282 & 0.191 & 0.038 & 0.099 & 1.755 & 0.240 & 0.200 & 0.000471 & 4545.1 & 0.172 \\
\hline 55 & 0 & + & - & 0 & 0 & - & 0 & 0.284 & 0.200 & 0.036 & 0.099 & 1.755 & 0.240 & 0.242 & 0.000446 & 4271.1 & 0.131 \\
\hline 56 & 0 & 0 & 0 & 0 & 0 & 0 & 0 & 0.284 & 0.191 & 0.038 & 0.099 & 1.755 & 0.241 & 0.242 & 0.000381 & 5379.9 & 0.146 \\
\hline 57 & 0 & 0 & 0 & + & + & + & 0 & 0.284 & 0.191 & 0.038 & 0.101 & 1.830 & 0.241 & 0.242 & 0.000471 & 4545.1 & 0.172 \\
\hline 58 & + & 0 & + & 0 & - & 0 & 0 & 0.286 & 0.191 & 0.039 & 0.099 & 1.680 & 0.241 & 0.242 & 0.000446 & 4271.1 & 0.131 \\
\hline 59 & + & 0 & + & 0 & + & 0 & 0 & 0.286 & 0.191 & 0.039 & 0.099 & 1.830 & 0.241 & 0.242 & 0.000381 & 5379.9 & 0.146 \\
\hline 60 & 0 & 0 & + & - & 0 & 0 & + & 0.284 & 0.191 & 0.039 & 0.097 & 1.755 & 0.241 & 0.285 & 0.000471 & 4545.1 & 0.172 \\
\hline 61 & 0 & - & + & 0 & 0 & + & 0 & 0.284 & 0.183 & 0.039 & 0.099 & 1.755 & 0.241 & 0.242 & 0.000446 & 4271.1 & 0.131 \\
\hline 62 & - & 0 & - & 0 & - & 0 & 0 & 0.282 & 0.191 & 0.036 & 0.099 & 1.680 & 0.241 & 0.242 & 0.000381 & 5379.9 & 0.146 \\
\hline
\end{tabular}

e-ISSN: 2289-7771 
Table 3. Regression coefficient values for volume of cast 1(BBD), density of cast 1 and weight loss

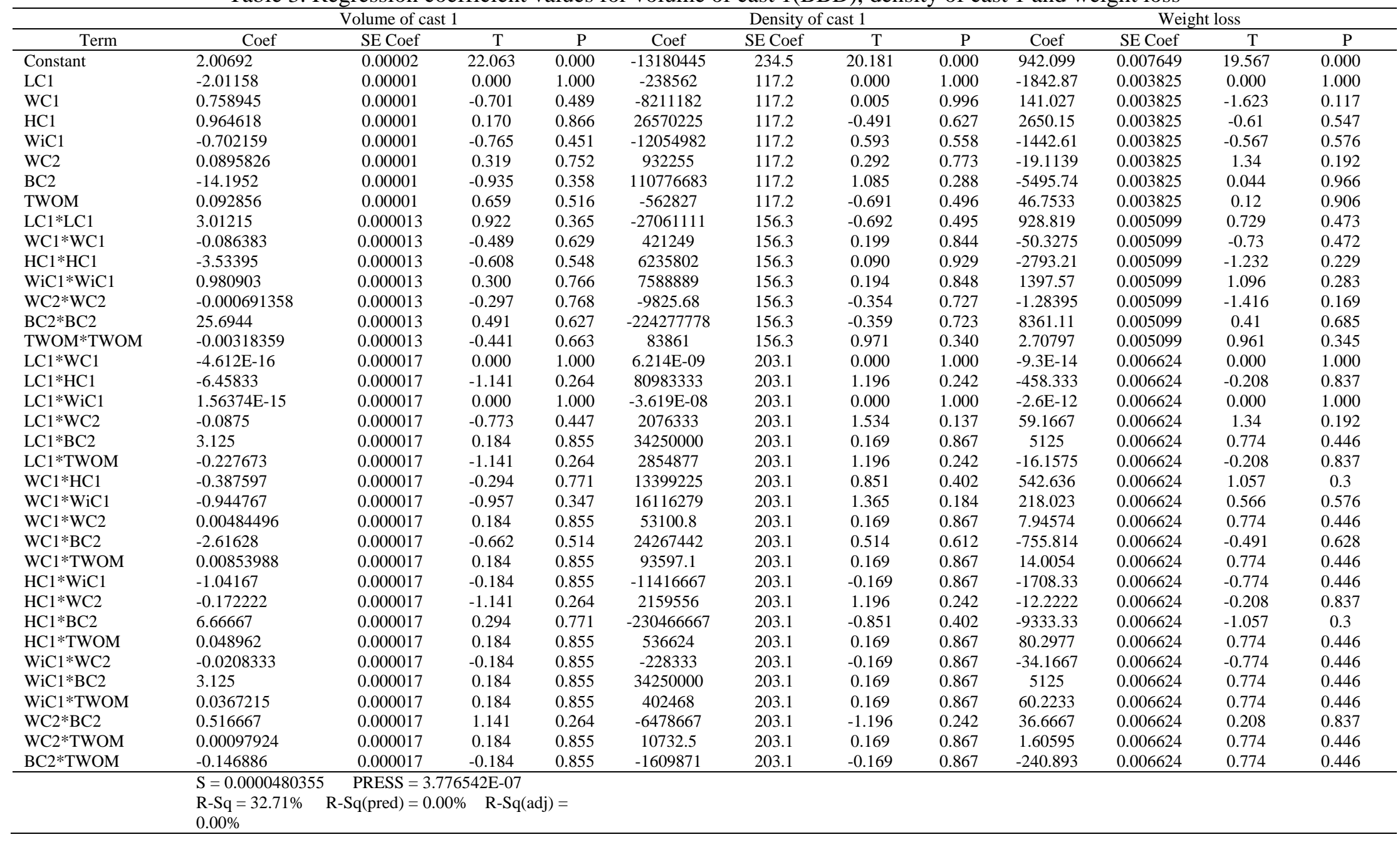

e-ISSN: $2289-7771$ 
Table 4. ANOVA Table for volume of cast 1, density of cast 1 and weight loss (BBD)

\begin{tabular}{|c|c|c|c|c|c|c|c|c|c|c|c|c|c|c|c|c|}
\hline \multirow[b]{2}{*}{ Source } & \multirow[b]{2}{*}{ DF } & \multicolumn{5}{|c|}{ Volume of cast 1} & \multicolumn{5}{|c|}{ Density of cast 1} & \multicolumn{5}{|c|}{ Weight loss } \\
\hline & & Seq SS & Adj SS & Adj MS & $\mathrm{F}$ & $\mathrm{P}$ & Seq SS & Adj SS & Adj MS & $F$ & $\mathrm{P}$ & Seq SS & Adj SS & Adj MS & $\mathrm{F}$ & $\mathrm{P}$ \\
\hline Regression & 35 & 0.000000 & 0.000000 & 0.000000 & 0.36 & 0.997 & 5396935 & 5396935 & 154198 & 0.47 & 0.982 & 0.008440 & 0.008440 & 0.000241 & 0.69 & 0.851 \\
\hline Linear & 7 & 0.000000 & 0.000000 & 0.000000 & 0.36 & 0.918 & 769595 & 769595 & 109942 & 0.33 & 0.931 & 0.001804 & 0.001804 & 0.000258 & 0.73 & 0.645 \\
\hline LC1 & 1 & 0.000000 & 0.000000 & 0.000000 & 0.00 & 1.000 & 0 & 0 & 0 & 0.00 & 1.000 & 0.000000 & 0.000000 & 0.000000 & 0.00 & 1.000 \\
\hline WC1 & 1 & 0.000000 & 0.000000 & 0.000000 & 0.49 & 0.489 & 7 & 7 & 7 & 0.00 & 0.996 & 0.000925 & 0.000925 & 0.000925 & 2.64 & 0.117 \\
\hline $\mathrm{HC} 1$ & 1 & 0.000000 & 0.000000 & 0.000000 & 0.03 & 0.866 & 79672 & 79672 & 79672 & 0.24 & 0.627 & 0.000131 & 0.000131 & 0.000131 & 0.37 & 0.547 \\
\hline WiC1 & 1 & 0.000000 & 0.000000 & 0.000000 & 0.59 & 0.451 & 116149 & 116149 & 116149 & 0.35 & 0.558 & 0.000113 & 0.000113 & 0.000113 & 0.32 & 0.576 \\
\hline WC2 & 1 & 0.000000 & 0.000000 & 0.000000 & 0.10 & 0.752 & 28153 & 28153 & 28153 & 0.09 & 0.773 & 0.000630 & 0.000630 & 0.000630 & 1.80 & 0.192 \\
\hline $\mathrm{BC} 2$ & 1 & 0.000000 & 0.000000 & 0.000000 & 0.87 & 0.358 & 388214 & 388214 & 388214 & 1.18 & 0.288 & 0.000001 & 0.000001 & 0.000001 & 0.00 & 0.966 \\
\hline TWOM & 1 & 0.000000 & 0.000000 & 0.000000 & 0.43 & 0.516 & 157399 & 157399 & 157399 & 0.48 & 0.496 & 0.000005 & 0.000005 & 0.000005 & 0.01 & 0.906 \\
\hline Square & 7 & 0.000000 & 0.000000 & 0.000000 & 0.35 & 0.922 & 688831 & 688831 & 98404 & 0.30 & 0.948 & 0.002862 & 0.002862 & 98404 & 1.16 & 0.356 \\
\hline $\mathrm{LC} 1 * \mathrm{LC} 1$ & 1 & 0.000000 & 0.000000 & 0.000000 & 0.85 & 0.365 & 206288 & 158178 & 158178 & 0.48 & 0.495 & 0.000250 & 0.000186 & 0.000186 & 0.53 & 0.473 \\
\hline $\mathrm{WC} 1 * \mathrm{WC} 1$ & 1 & 0.000000 & 0.000000 & 0.000000 & 0.24 & 0.629 & 7718 & 13104 & 13104 & 0.04 & 0.844 & 0.000193 & 0.000187 & 0.000187 & 0.53 & 0.472 \\
\hline $\mathrm{HC} 1 * \mathrm{HC} 1$ & 1 & 0.000000 & 0.000000 & 0.000000 & 0.37 & 0.548 & 610 & 2658 & 2658 & 0.01 & 0.929 & 0.000680 & 0.000533 & 0.000533 & 1.52 & 0.229 \\
\hline $\mathrm{WiC} 1 * \mathrm{WiC} 1$ & 1 & 0.000000 & 0.000000 & 0.000000 & 0.09 & 0.766 & 9323 & 12440 & 12440 & 0.04 & 0.848 & 0.000451 & 0.000422 & 0.000422 & 1.20 & 0.283 \\
\hline $\mathrm{WC} 2 * \mathrm{WC} 2$ & 1 & 0.000000 & 0.000000 & 0.000000 & 0.09 & 0.768 & 65580 & 41239 & 41239 & 0.13 & 0.727 & 0.000940 & 0.000704 & 0.000704 & 2.01 & 0.169 \\
\hline $\mathrm{BC} 2 * \mathrm{BC} 2$ & 1 & 0.000000 & 0.000000 & 0.000000 & 0.24 & 0.627 & 88104 & 42441 & 42441 & 0.13 & 0.723 & 0.000024 & 0.000059 & 0.000059 & 0.17 & 0.685 \\
\hline TWOM*TWOM & 1 & 0.000000 & 0.000000 & 0.000000 & 0.19 & 0.663 & 311209 & 311209 & 311209 & 0.94 & 0.340 & 0.000325 & 0.000325 & 0.000325 & 0.92 & 0.345 \\
\hline Interaction & 21 & 0.000000 & 0.000000 & 0.000000 & 0.37 & 0.989 & 3938508 & 3938508 & 187548 & 0.57 & 0.905 & 0.003773 & 0.003773 & 187548 & 0.51 & 0.939 \\
\hline $\mathrm{LC} 1 * \mathrm{WC} 1$ & 1 & 0.000000 & 0.000000 & 0.000000 & 0.00 & 1.000 & 0 & 0 & 0 & 0.00 & 1.000 & 0.000000 & 0.000000 & 0.000000 & 0.00 & 1.000 \\
\hline $\mathrm{LC} 1 * \mathrm{HC} 1$ & 1 & 0.000000 & 0.000000 & 0.000000 & 1.30 & 0.264 & 472198 & 472198 & 472198 & 1.43 & 0.242 & 0.000015 & 0.000015 & 0.000015 & 0.04 & 0.837 \\
\hline $\mathrm{LC} 1 * \mathrm{WiC} 1$ & 1 & 0.000000 & 0.000000 & 0.000000 & 0.00 & 1.000 & 0 & 0 & 0 & 0.00 & 1.000 & 0.000000 & 0.000000 & 0.000000 & 0.00 & 1.000 \\
\hline $\mathrm{LC} 1 * \mathrm{WC} 2$ & 1 & 0.000000 & 0.000000 & 0.000000 & 0.60 & 0.447 & 776009 & 776009 & 776009 & 2.35 & 0.137 & 0.000630 & 0.000630 & 0.000630 & 1.79 & 0.192 \\
\hline $\mathrm{LC} 1 * \mathrm{BC} 2$ & 1 & 0.000000 & 0.000000 & 0.000000 & 0.03 & 0.855 & 9385 & 9385 & 9385 & 0.03 & 0.867 & 0.000210 & 0.000210 & 0.000210 & 0.60 & 0.446 \\
\hline LC1*TWOM & 1 & 0.000000 & 0.000000 & 0.000000 & 1.30 & 0.264 & 472198 & 472198 & 472198 & 1.43 & 0.242 & 0.000015 & 0.000015 & 0.000015 & 0.04 & 0.837 \\
\hline $\mathrm{WC} 1 * \mathrm{HC} 1$ & 1 & 0.000000 & 0.000000 & 0.000000 & 0.09 & 0.771 & 239017 & 239017 & 239017 & 0.72 & 0.402 & 0.000392 & 0.000392 & 0.000392 & 1.12 & 0.300 \\
\hline $\mathrm{WC} 1 * \mathrm{WiC} 1$ & 1 & 0.000000 & 0.000000 & 0.000000 & 0.92 & 0.347 & 614719 & 614719 & 614719 & 1.86 & 0.184 & 0.000113 & 0.000113 & 0.000113 & 0.32 & 0.576 \\
\hline $\mathrm{WC} 1 * \mathrm{WC} 2$ & 1 & 0.000000 & 0.000000 & 0.000000 & 0.03 & 0.855 & 9385 & 9385 & 9385 & 0.03 & 0.867 & 0.000210 & 0.000210 & 0.000210 & 0.60 & 0.446 \\
\hline $\mathrm{WC} 1 * \mathrm{BC} 2$ & 1 & 0.000000 & 0.000000 & 0.000000 & 0.44 & 0.514 & 87111 & 87111 & 87111 & 0.26 & 0.612 & 0.000084 & 0.000084 & 0.000084 & 0.24 & 0.628 \\
\hline WC1*TWOM & 1 & 0.000000 & 0.000000 & 0.000000 & 0.03 & 0.855 & 9385 & 9385 & 9385 & 0.03 & 0.867 & 0.000210 & 0.000210 & 0.000210 & 0.60 & 0.446 \\
\hline $\mathrm{HC} 1 * \mathrm{WiC} 1$ & 1 & 0.000000 & 0.000000 & 0.000000 & 0.03 & 0.855 & 9385 & 9385 & 9385 & 0.03 & 0.867 & 0.000210 & 0.000210 & 0.000210 & 0.60 & 0.446 \\
\hline $\mathrm{HC} 1 * \mathrm{WC} 2$ & 1 & 0.000000 & 0.000000 & 0.000000 & 1.30 & 0.264 & 472198 & 472198 & 472198 & 1.43 & 0.242 & 0.000015 & 0.000015 & 0.000015 & 0.04 & 0.837 \\
\hline $\mathrm{HC} 1 * \mathrm{BC} 2$ & 1 & 0.000000 & 0.000000 & 0.000000 & 0.09 & 0.771 & 239017 & 239017 & 239017 & 0.72 & 0.402 & 0.000392 & 0.000392 & 0.000392 & 1.12 & 0.300 \\
\hline $\mathrm{HC} 1 * \mathrm{TWOM}$ & 1 & 0.000000 & 0.000000 & 0.000000 & 0.03 & 0.855 & 9384 & 9384 & 9384 & 0.03 & 0.867 & 0.000210 & 0.000210 & 0.000210 & 0.60 & 0.446 \\
\hline $\mathrm{WiC} 1 * \mathrm{WC} 2$ & 1 & 0.000000 & 0.000000 & 0.000000 & 0.03 & 0.855 & 9384 & 9384 & 9384 & 0.03 & 0.867 & 0.000210 & 0.000210 & 0.000210 & 0.60 & 0.446 \\
\hline $\mathrm{WiC} 1 * \mathrm{BC} 2$ & 1 & 0.000000 & 0.000000 & 0.000000 & 0.03 & 0.855 & 9385 & 9385 & 9385 & 0.03 & 0.867 & 0.000210 & 0.000210 & 0.000210 & 0.60 & 0.446 \\
\hline WiC $1 *$ TWOM & 1 & 0.000000 & 0.000000 & 0.000000 & 0.03 & 0.855 & 9385 & 9385 & 9385 & 0.03 & 0.867 & 0.000210 & 0.000210 & 0.000210 & 0.60 & 0.446 \\
\hline $\mathrm{WC} 2 * \mathrm{BC} 2$ & 1 & 0.000000 & 0.000000 & 0.000000 & 1.30 & 0.264 & 472198 & 472198 & 472198 & 1.43 & 0.242 & 0.000015 & 0.000015 & 0.000015 & 0.04 & 0.837 \\
\hline WC $2 *$ TWOM & 1 & 0.000000 & 0.000000 & 0.000000 & 0.03 & 0.855 & 9385 & 9385 & 9385 & 0.03 & 0.867 & 0.000210 & 0.000210 & 0.000210 & 0.60 & 0.446 \\
\hline BC2*TWOM & 1 & 0.000000 & 0.000000 & 0.000000 & 0.03 & 0.855 & 9384 & 9384 & 9384 & 0.03 & 0.867 & 0.000210 & 0.000210 & 0.000210 & 0.60 & 0.446 \\
\hline Residual Error & 26 & 0.000000 & 0.000000 & 0.000000 & & & 8577389 & 8577389 & 329900 & & & 0.009127 & 0.009127 & 329900 & & \\
\hline Lack-of-Fit & 21 & 0.000000 & 0.000000 & 0.000000 & 1.42 & 0.375 & 7243119 & 7243119 & 344910 & 1.29 & 0.421 & 0.007406 & 0.007406 & 344910 & 1.02 & 0.545 \\
\hline Pure Error & 5 & 0.000000 & 0.000000 & 0.000000 & & & 1334270 & 1334270 & 266854 & & & 0.001721 & 0.001721 & 266854 & & \\
\hline Total & 61 & 0.000000 & & & & & 13974324 & & & & & 0.017567 & & & & \\
\hline
\end{tabular}

e-ISSN: 2289-7771 


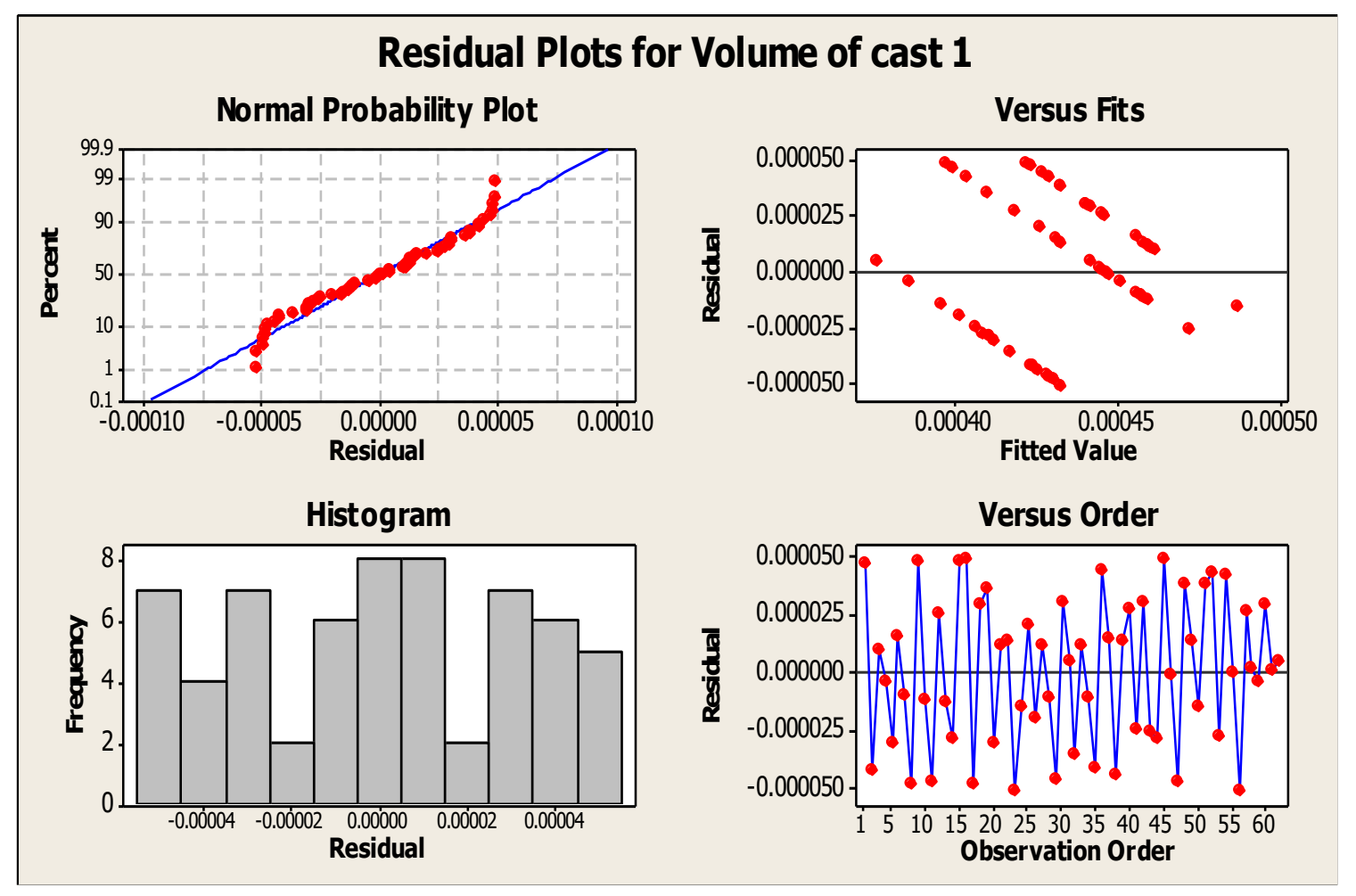

Figure 1. Residual plots for volume of cast 1 


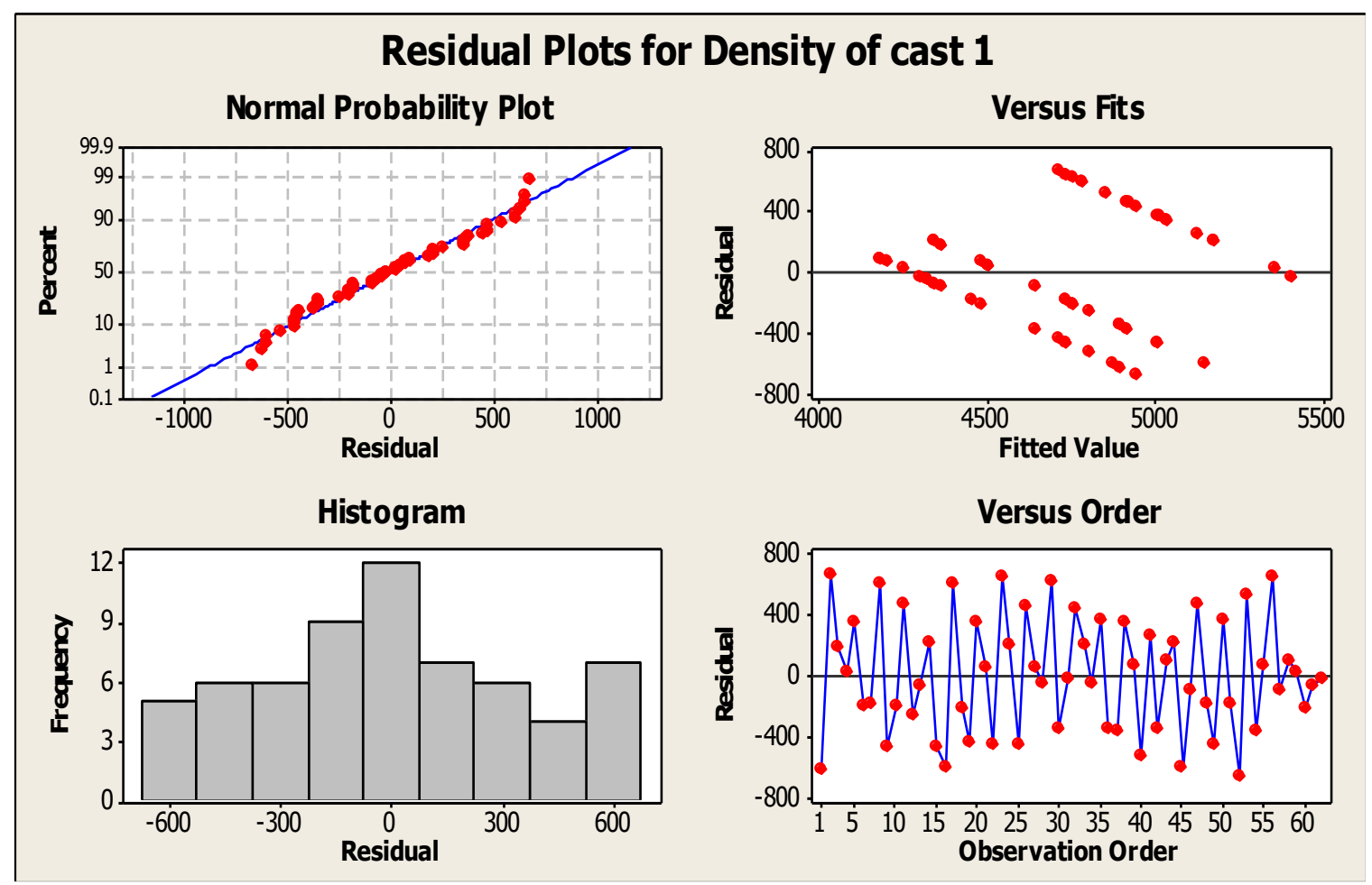

Figure 2. Residual plots for density of cast 1

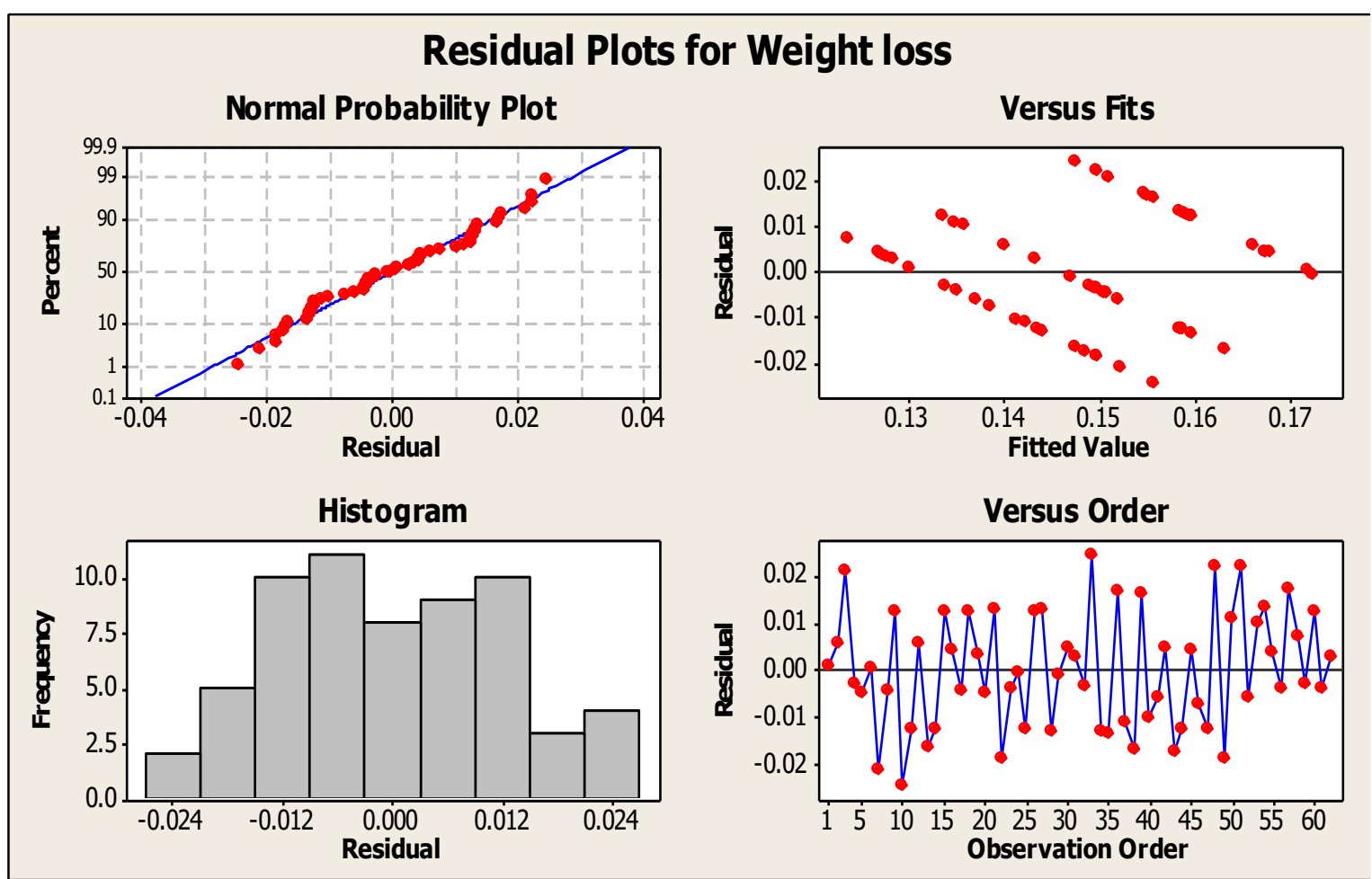

Figure 3. Residual plots for weight loss 
Figure 4 shows the main effect plot of volume of cast, which shows that $\mathrm{BC} 2$ has the highest significant effect on Volume of cast 1. TWOM have the highest effect on density of cast 1 as shown in Figure 5. Figure 6 shows that $\mathrm{WiCl}$ has the highest significant effect on weight loss.

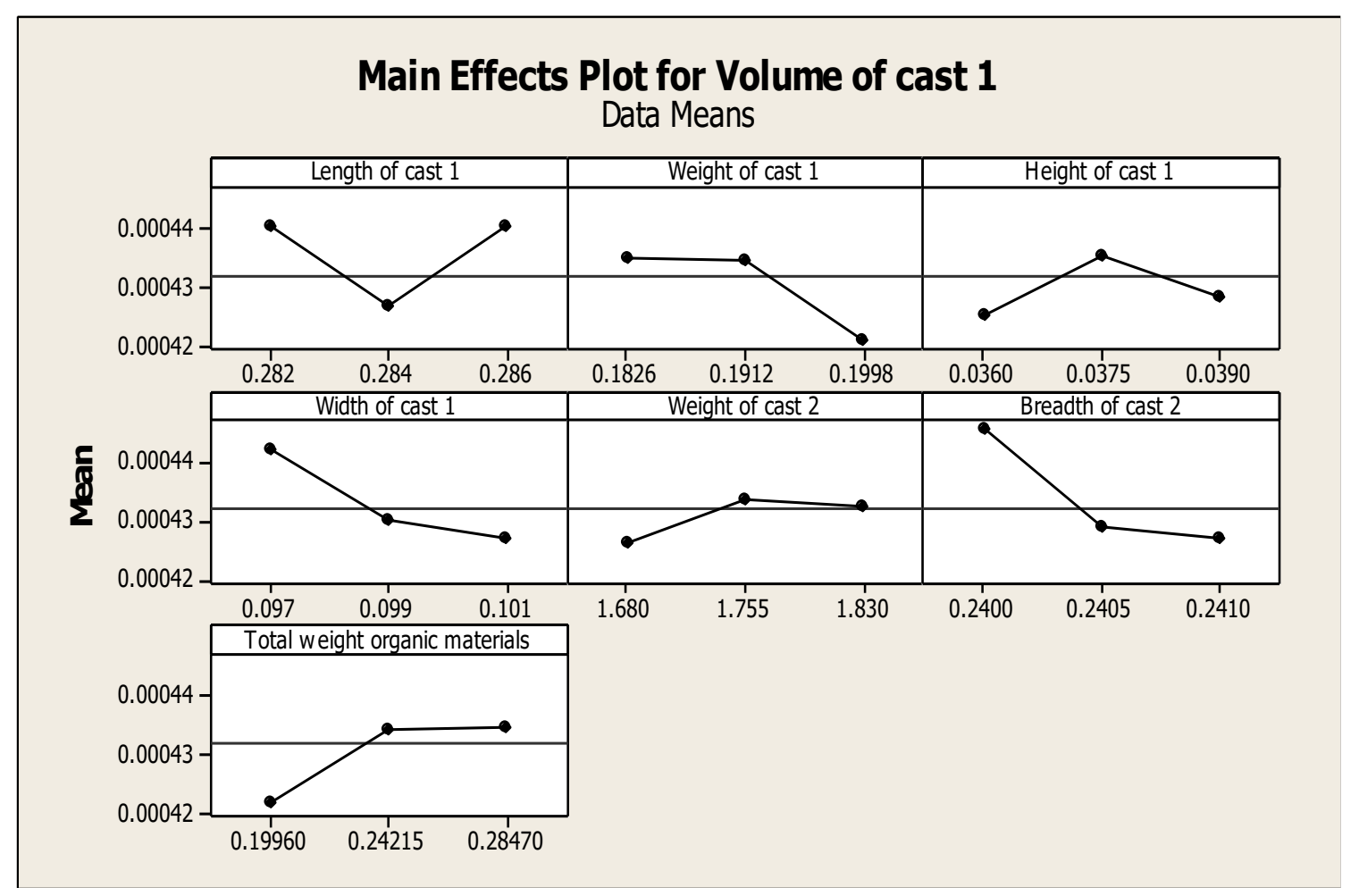

Figure 4. Main effect plot of Volume of cast 1 


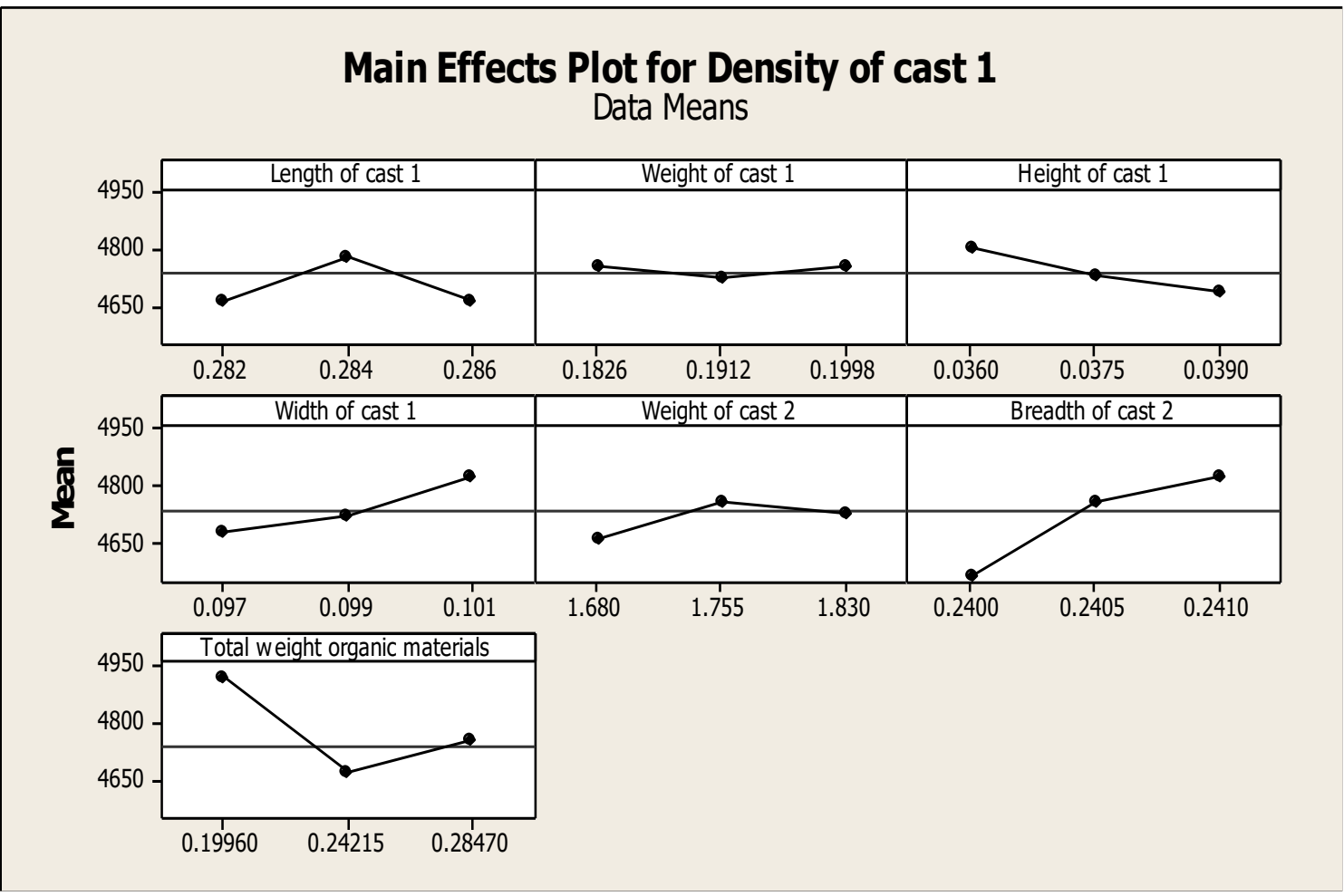

Figure 5. Main effect plot of density of cast 1

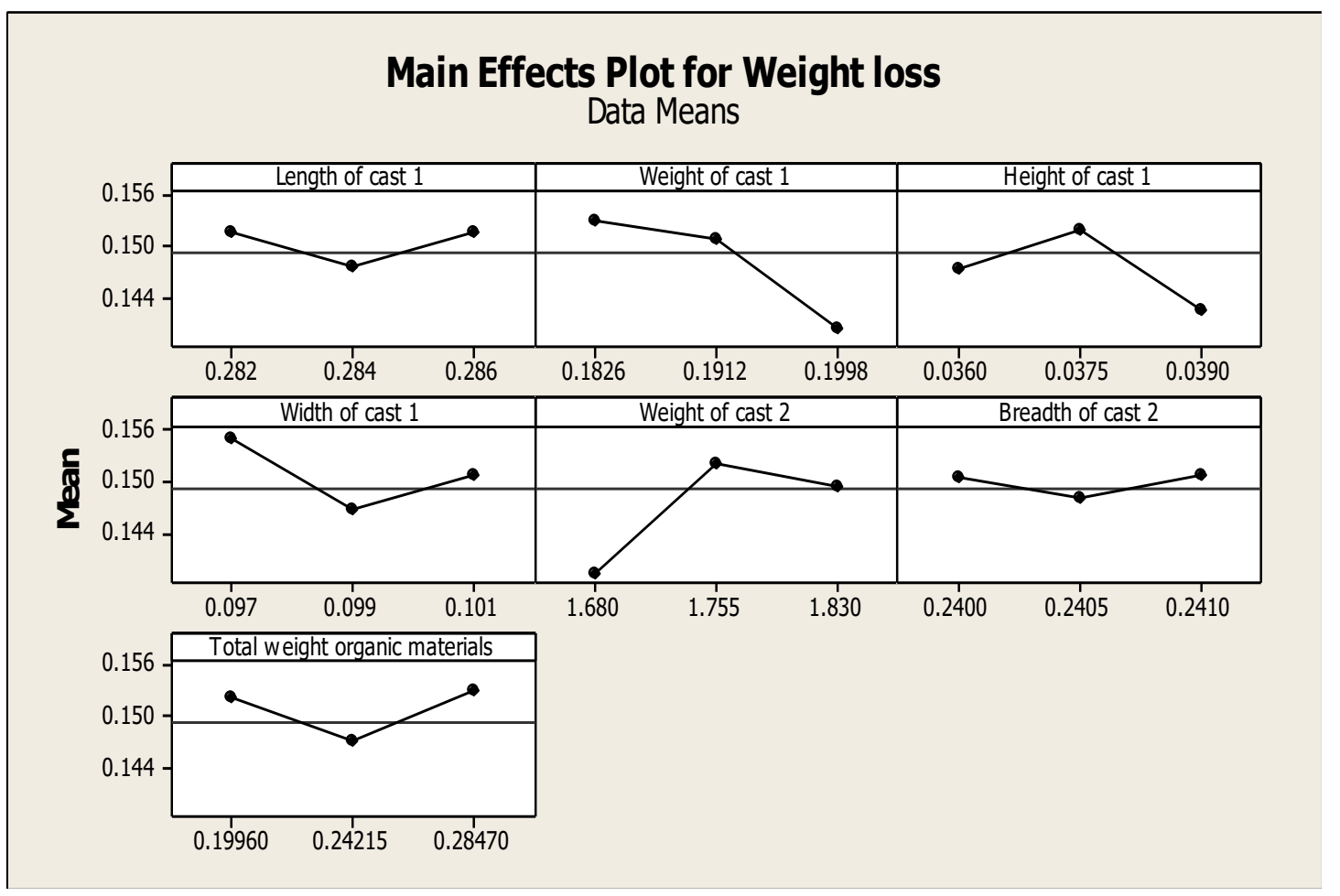

Figure 6. Main effect plot of weight loss 


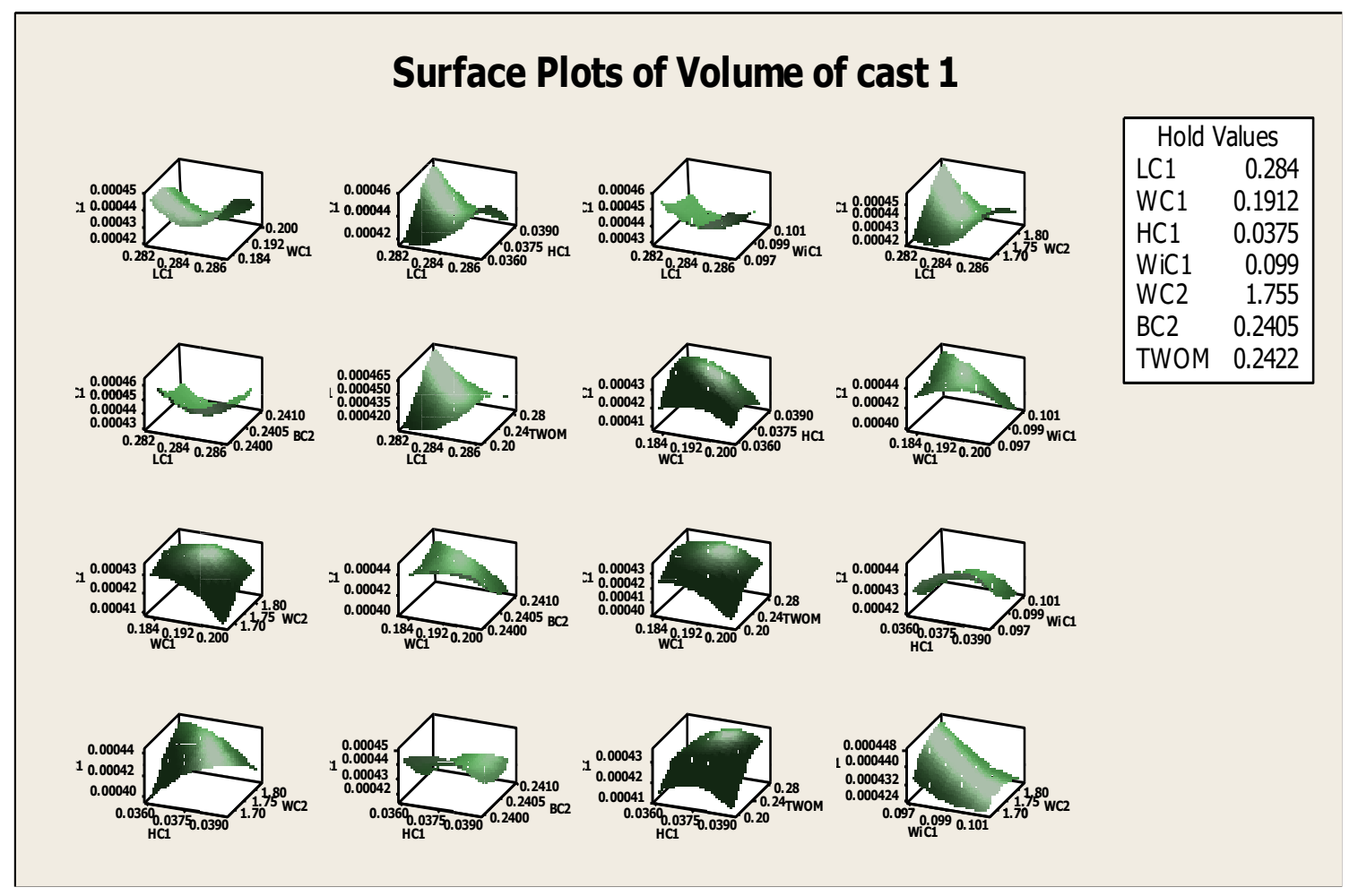

Figure 7a. Surface plots of volume of cast 1

Figure 7a shows the surface plot of volume of cast 1 where at a particular of length of cast 1 with a particular value of every other factor, volume of cast 1 tends to increase. It tends to decrease at a particular of weight of cast 1 with a particular value of every other factor and also at a particular of height of cast 1 with a particular value of width of cast 1 , weight of cast 2 , breadth of cast 2 and total weight of organic materials. In Figure 7b, volume of cast 1 decreases when width of cast 1 increases with a decrease in breadth of cast 2, total weight of organic materials and at a particular value of weight of cast 2 and also when weight of cast 2 increases with a decrease in breadth of cast 2 . At a particular value of weight of cast 2 with a particular value of total weight of organic materials and a particular value of breadth of cast 2 with a particular value of total weight of organic materials, volume of cast 1 tends to decrease and increase respectively. 


\section{Surface Plots of Volume of cast 1}
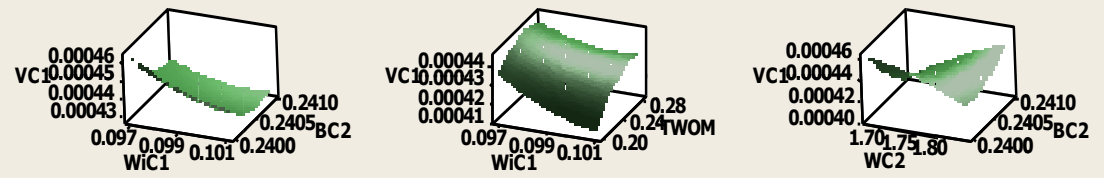

\begin{tabular}{|lr|}
\hline \multicolumn{2}{|c|}{ Hold Values } \\
LC1 & 0.284 \\
WC1 & 0.1912 \\
HC1 & 0.0375 \\
WiC1 & 0.099 \\
WC2 & 1.755 \\
BC2 & 0.2405 \\
TWOM & 0.2422 \\
\hline
\end{tabular}
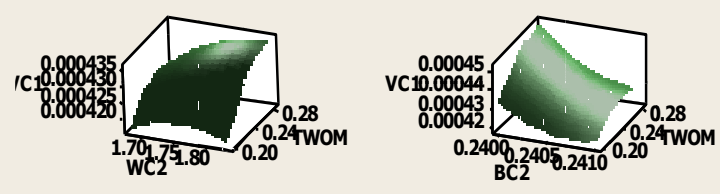

Figure $7 \mathrm{~b}$. Surface plots of the volume of cast 1

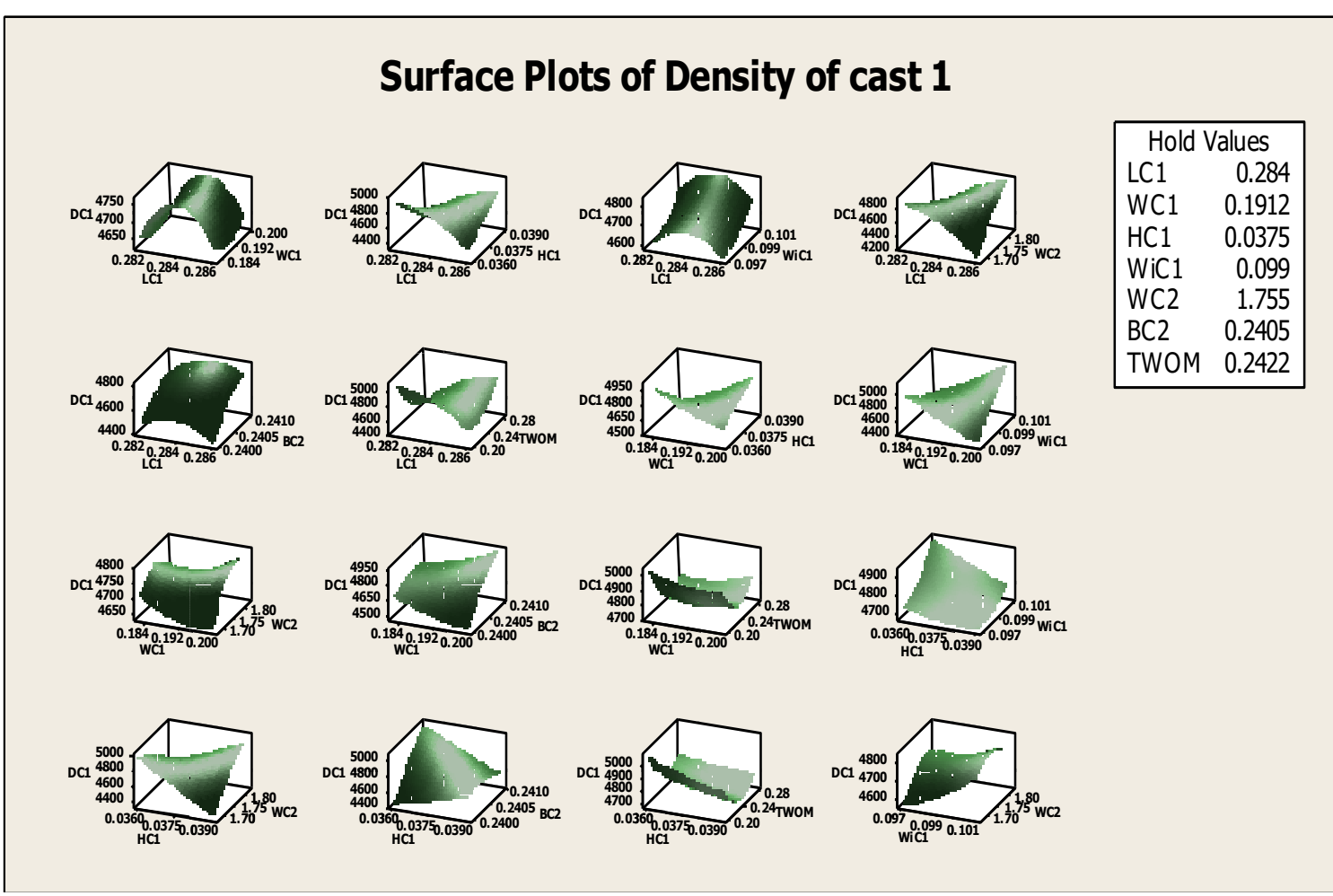

Figure 7c. Surface plots of the density of cast 1

e-ISSN: $2289-7771$ 
In Figure 7c, at a particular of length of cast 1 with a particular value of weight of cast 1, breadth of cast 2, a decrease in width of cast 1 and total weight of organic materials and also an increase in length of cast 1 with a decrease in height of cast 1 and weight of cast 2, density of cast 1 tends to decrease. Density of cast 1 decreases, when the weight of cast 1 increases with a decrease in the height of cast 1 , the width of cast 1 and breadth of cast 2, and also at a particular value of weight of cast 1 with a decrease in weight of cast 2 , it increases at a particular value of the weight of cast 1 with a particular value of total weight of organic materials. An increase in the height of cast 1 with a decrease in the breadth of cast 1 , the weight of cast 2, breadth of cast 2 and at a particular value of total weight of organic materials, Density of cast 1 decreases. In Figure 7d, increase the width of cast 1 with a decrease in weight of cast 2 and breadth of cast 2 , at a particular value width of cast 1 with a particular value of the total weight of organic materials, the density of cast 1 decreases. It also decreases when the weight of cast 2 increases with a decrease in breadth of cast 2, when at a particular value of weight of cast 2 with a particular value total weight of organic materials and at a particular value of breadth of cast 2 with a particular value of the total weight of organic materials.

\section{Surface Plots of Density of cast 1}
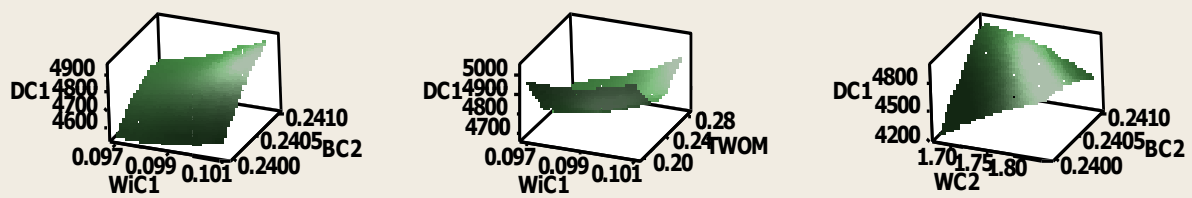

\begin{tabular}{|lr|}
\hline \multicolumn{2}{|c|}{ Hold Values } \\
LC1 & 0.284 \\
WC1 & 0.1912 \\
HC1 & 0.0375 \\
WiC1 & 0.099 \\
WC2 & 1.755 \\
BC2 & 0.2405 \\
TWOM & 0.2422 \\
\hline
\end{tabular}
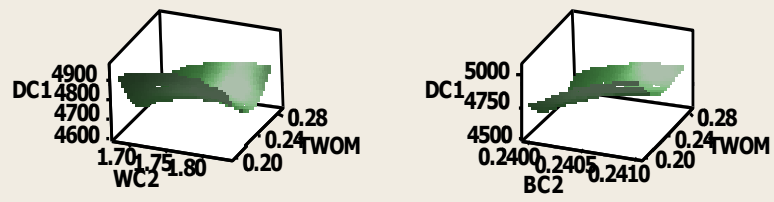

Figure 7 d. Surface plots of the density of cast 1 


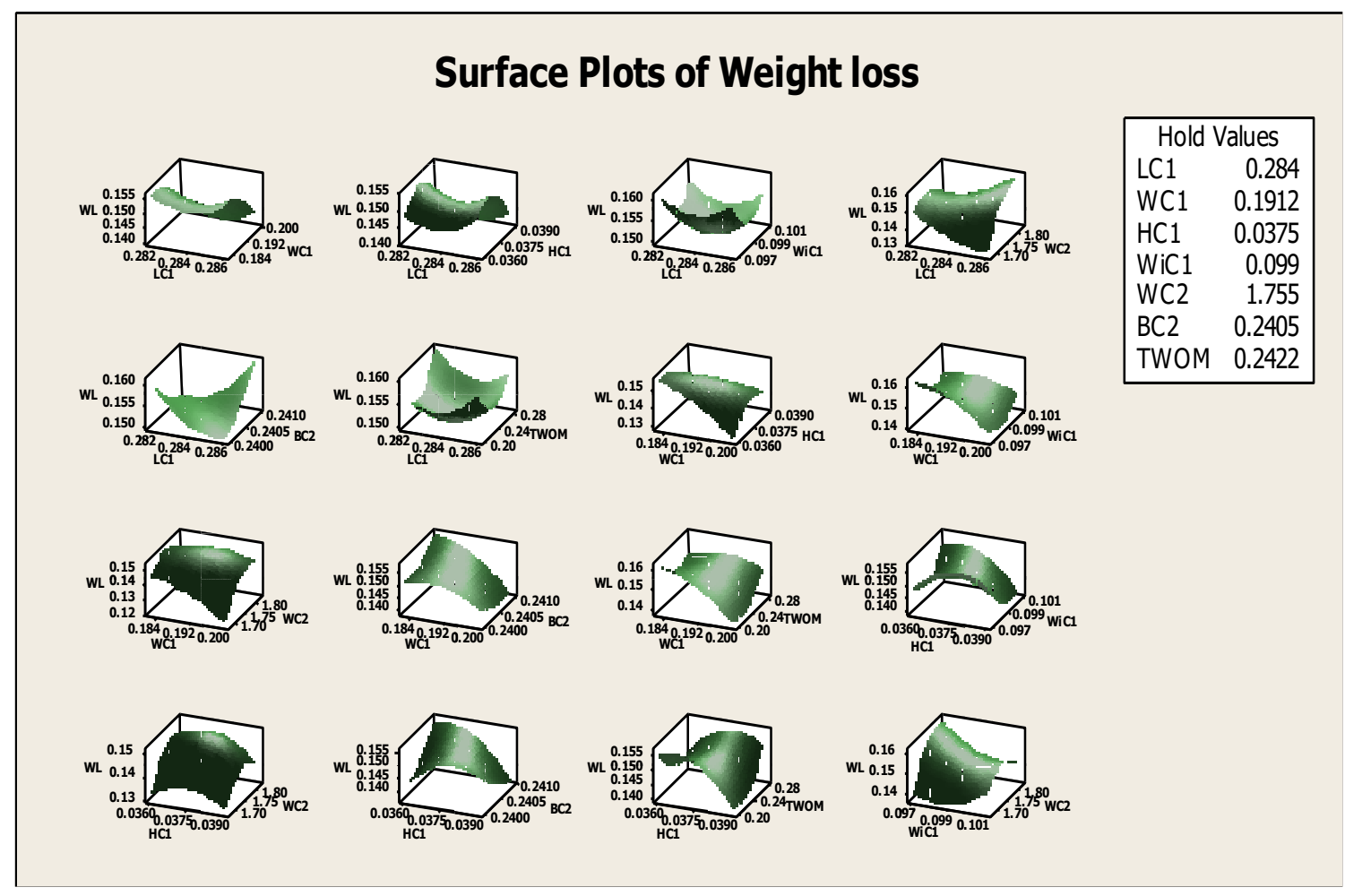

Figure 7e. Surface plots of weight loss

Weight loss tends to increase at a particular value of length of cast 1 with a particular value of weight of cast 1 , height of cast 1 , width of cast 1 and total weight of organic materials and decrease when length of cast 1 increases with a decrease in weight of cast 2 and breadth of cast 2 . An increase in weight of cast 1 with a particular value of other factors, weight loss decreases. It tends to decrease at a particular value of height of cast 1 with a particular value of width of cast 1 , weight of cast 2, breadth of cast and total weight of organic materials. Weight loss tends to increase at a particular value of width of cast 1 with a particular value of weight of cast 2 and total weight of organic materials and decrease when width of cast 1 increases with a decrease in breadth of cast 2. Weight loss tends to decrease at a particular value of weight of cast 2 with a particular value of breadth of cast 2 and total weight of organic materials and tends to increase at a particular value of breadth of cast 2 with a particular value of total weight of organic materials. 


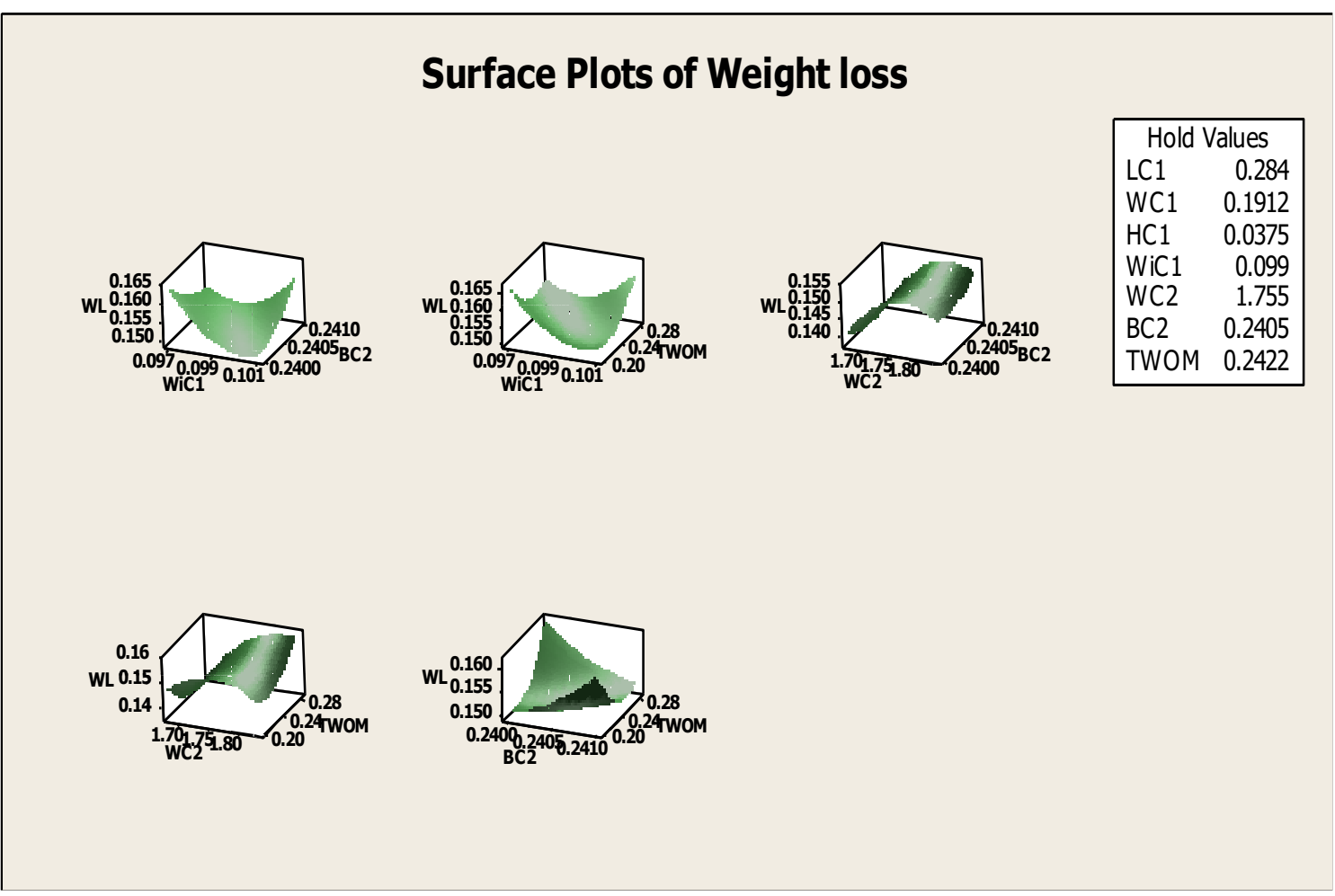

Figure 7f. Surface plots of weight loss

\subsection{Research contributions}

The following are the contributions of this paper to knowledge:

1. It proposes a general approach to represent the optimisation of casting geometries of samples processed through sand casting in a two-phase dimension by the Box-Behnken design response surface optimisation of A356 alloy/organic composite. The reinforcement is the combined powder pineapple sucker, particulate of droppings from the Delonix regia tree and abori wood powder.

2. In terms of application, it is the first time that Box-Behnken approach will be applied to the optimisation of wheel covers for automobiles.

3. The Box-Behnken approach provides a basis to experiment the theory about sand casting and weight loss as an independent variable. Further theories, for example, integrating grey relational analysis with Box-Behnken approach for enhanced optimisation could be pursued. Moreover, since weight loss is an economic concern as it could be transformed into economic material loss, it could be related to engineering economic principles to determine the impact of such losses on the total production and the fabrication systems as a whole. 


\section{Conclusions}

The present work has established the optimisation behaviour of an A356 alloy reinforced with powdered pineapple stalk, abori wood and Delonix regia under the sand casting process. From the attained outcomes, the following can be concluded:

1. The Box-Behnken design was used as a predictive model to evaluate the A356 alloy/ powdered pineapple stalk, abori wood and Delonix regia composite. The response surface methodology developed was found to be statistically valid and reliable in the context of factors tested in the model.

2. The principal result is that the case shows that $32.71 \%$ in light output which is the R-sq value, the model is overfitted because the R-sq(pred) value, the regression f-value of 0.36 shows a low significance for the regression model and also shows that linear regression, square and interaction of A356 alloy model are insignificant.

\section{References}

[1] Raghupathy R. and Amirthagadeswaran K.S. (2017). Parametric Optimisation and Solidification Analysis of Grey Cast Pump Adapter Castings using DOE and CAE-A Case Study, Australian Journal of Mechanical Engineering, Vol. 15, No. 1, 27-35.

[2] Pedersen T.H. and Lenau T.A. (2010). Variable Geometry Casting of Concrete Elements using Pin-Type Tooling, Journal of Manufacturing Science and Engineering, Vol. 132, No. 6, 1-10.

[3] Hardin R.A., Choi K.K., Gaul N.J. and Beckermann C. (2015). Reliability Based Casting Process Design Optimisation, International Journal of Cast Metals Research, Vol. 28, No. 3, 181-192.

[4] El-Sayed M.A., Hassanin H. and Essa K.. (2016). Effect of Casting Practice on the Reliability of Al Cast Alloys, International Journal of Cast Metals Research, Vol. 29, No. 6, 350-354.

[5] Diószegi A., Svidró P., Elmquist L. and Dugic I. (2016). Defect Formation Mechanisms in Lamellar Graphite Iron Related to the Casting Geometry, International Journal of Cast Metals Research, Vol. 29, No. 5, 279-285.

[6] Auger J.-M. (2017). Local Definition for Surface-Based Geometrical Modulus and Use in Automated Casting Cooling Determination, International Journal of Cast Metals Research, Vol. 30, No. 6, 322-336.

[7] Stadler F, Antrekowitsch H., Fragner W., Kaufmann H. and Uggowitzer P.J. (2012). Effect of Main Alloying Elements on Strength of Al-Si Foundry Alloys at Elevated Temperatures, International Journal of Cast Metals Research, Vol. 25, No. 4, 215-224.

[8] Raghupathy R. and Amirthagadeswaran K.S. (2013). Optimisation of Casting Process Based on Box Behnken Design and Response Surface Methodology, International Journal for Quality Research, Vol. 8, No. 4, 569582

[9] Patel M., Krishna P. and Parappagoudar M. B. (2015). Modelling of Squeeze Casting Process Using Design of Experiments and Response Surface Methodology, International Journal of Cast Metals Research, Vol. 28, No. 3, 167-180.

[10] Das P., Bhurya B., Samanta S.K.. and Duta P. (2019). Studies on Die Filling of A356 Al Alloy and Development of a Steering Knuckle Component Using Rheo Pressure Die Casting System, Journal of Materials Processing Technology, Vol. 271, $293-311$.

[11] Asawarungsaengkul K. and Yathiphat S. (2015). Quality Improvement in a Low Pressure Die Casting Process of Alloy Wheels by Applying Box-Behnken Design, Proceedings of the International Conference on Data Engineering 2015 (DaEng-2015), 375-382

e-ISSN: 2289-7771 
[12] Nwafor S.C., Oke S.A. and Ayanladun C.A. (2019). Taguchi Optimisation of Cast Geometries for A356/Organic Particulate Aluminium Alloy Composites Using a Two-Phase Casting Process, Journal of Applied Science and Process Engineering, Vol. 6, No. 2, 386-412.

[13] Balasubramanian K., Nataraj M. and Duraisany P. (2019). Machinability analysis and application of response surface approach on CNC turning of LM6/SiCp composites, Materials and Manufacturing Processes, Vol. 34, No.12, 1389-1400.

[14] Kumar A., Singh H. and Kumar V. (2018). Study the Parametric Effect of Abrasive Water Jet Machining on Surface Roughness of Inconel 718 using RSM-BBD Techniques, Materials and Manufacturing Processes, Vol. 33, No. 13, 1483-1490

[15] Wang D., Sun J., Dong A., Shu D., Zhu G. and Sun B. (2018). An Optimisation Method of Gating System for Impeller by RSM and Simulation in Investment Casting, The International Journal of Advanced Manufacturing Technology, Vol. 98, 3105-3114

[16] Pai D., Rao S., Shetty R. and Nayak R. (2010). Application of Response Surface Methodology on Surface Roughness in Grinding of Aerospace Materials (6061A1-15Vol\%SiC25p), ARPN Journal of Engineering and Applied Sciences, Vol. 5, No. 6, 23-28

[17] Nwobi-Okoye C.C. and Ochieze B.Q. (2018). Age Hardening Process Modeling and Optimisation of Aluminum Alloy A356/Cow Horn Particulate Composite for Brake Drum Application using RSM, ANN and Simulated Annealing, Defence Technology, Vol. 14, No. 4, 336-345.

[18] Radhika N. and Raghu R. (2018). Study on Three-Body Abrasive Wear Behaviour of Functionally Graded Al/TiB2 Composite Using Response Surface Methodology, Particulate Science and Technology: An International Journal, Vol.36, No.7, 816-823.

[19] Patel M., Krishna G.C.P., and Parappagoudar B. (2015). Modeling of Squeeze Casting Process Using Design of Experiments and Response Surface Methodology, International Journal of Cast Metals Research, Vol.28, No.3, 167-180.

[20] Bawono B., Anggoro P.W., Bayuseno A.P., Jamari J. and Tauviquirrahman M. (2019). Milling Strategy Optimised for Orthotics Insole to Enhance Surface Roughness and Machining Time by Taguchi and Response Surface Methodology, Journal of Industrial and Production Engineering, Vol.36, No.4, 237-257.

[21] Adalarasan R., Santhanakumar M. and Shanmugasundaram A. (2017). Investigation in Solid-State Joining of $\mathrm{Al} / \mathrm{SiC}_{\mathrm{Al}} \mathrm{O}_{3}$ Composite Using Grey-Based Desirability (GBD) and Response Surface Plots, Journal of Chinese Institute of Engineers, Vol. 40, No.1, 55-65.

[22] Mwaniki W.A., Joseph K., John M., Wellington M., Catherine K., Bramuel E. (2017). Application of Response Surface Methodology for Determining Optimal Factors in Maximisation of Maize Grain Yield and Total Microbial Count in Long Term Agricultural Experiment, Kenya, Science Journal of Applied Mathematics and Statistics, Vol. 5, No. 6, 200-209.

[23] Purohit A., Satapathy A., Swain P.T.R., Patnaik P.K.. (2020). Analysis Of Sliding Wear Behavior of LD Sludge Filled Epoxy Composites Using Response Surface Methodology, Materials Today: Proceedings, In press.

[24] Alvarez M.J., Iizarbe I., Viles E. and Tanco M. (2009). The Use of Genetic Algorithms in Response Surface Methodology, Quality Technology and Quantitative Management, Vol. 6, No.3, 295-307.

[25] Mohal S. and Kumar H. (2016). Parametric Optimisation of Multi-Walled Carbon Nanotube-Assisted Electric Discharge Machining of Al-10\%SiCp Metal Composite by Response Surface Methodology, Materials and Manufacturing Processes, Vol.32, No.3, 263-273.

[26] Palanikumar K.. and Karthikeyan R. (2006). Optimal Machining Conditions for Turning of Particulate Metal Matrix Composites Using Taguchi and Response Surface Methodologies, Machining Science and Technology: An International Journal, Vol. 10, No.4, 417-433.

e-ISSN: 2289-7771 
[27] Palanikumar K., Muthukrishnan N. and Hariprasad K.S. (2008). Surface Roughness Parameters Optimisation in Machining A356/SiC/20p Metal Matrix Composites by PCD Tool Using Response Surface Methodology and Desirability Function, Machining Science and Technology: An International Journal, Vol. 12, No. 4, 529-545.

[28] Ochieze B.Q., Nwobi-Okoye C.C. and Atamuo P.N. (2018), Experimental Study of the Effect of Wear Parameters on the Wear Behavior of A356 Alloy/Cow Horn Particulate Composites, Defence Technology, Vol. 14 , No. $1,77-82$

[29] Abhishek K. (2011). Experimental Investigations on Machining of CFRP Composites: Study of Parametric Influence and Machining Performance Optimisation, Ph.D. Thesis, Department of Mechanical Engineering, National Institute of Technology, Rourkela, India

[30] Ochieze B.Q., Nwobi-Okoye C.C., Ochieze P.U.and Ochieze I.A. (2018). Microstructural and Properties Evaluation of A356 Alloy/Cow Horn Particulate Composites Produced by Spark Plasma Sintering, Journal of the Chinese Advanced Material Society, Vol. 6, No. 1, 30-43.

[31] Nwobi-Okoye C.C., Ochieze B. Q., Okiy S. (2019). Multi-Objective Optimisation and Modeling of Age Hardening Process Using ANN, ANFIS and Genetic Algorithm: Result from Aluminium Alloy A356/Cow Horn Particulate Composite, Journal of Materials Research and Technology, Vol 8, No. 3, 3054-3075.

[32] Subrahmanyam A.P.S.V.R., Naresh G. and Venkatesu V. (2018). Microstructure and Mechanical Properties of Rice Husk Ash Reinforced Aluminium Alloy (A356.2) Metal Matrix Composite, IOSR Journal of Engineering, Vol. 8, No. 6, 36-42.

[33] Prasad D.S. and Ramakrishna A. (2011). Production and Mechanical Properties of A356.2/RHA Composites, International Journal of Advanced Science and Technology, Vol. 33, pp. 51-58

[34] Prasad D.S. and Ramakrishna A. (2012). Tribological Properties of A356.2/RHA Composites, Journal of Materials Science and Technology, Vol. 28, No. 4, 367-372.

[35] Vinod, B., Ramanathan, S., Ananthi, V. and Selvakumar N. (2019). Fabrication and Characterization of Organic and in-Organic Reinforced A356 Aluminium Matrix Hybrid Composite by Improved Double-Stir Casting. Silicon Vol. 11, 817-829.

[36] Haque M.H., Ahmed R., Khan M.M. and Shahriar S. (2016). Fabrication, Reinforcement and Characterization of Metal Matrix Composites (MMCs) Using Rice Husk Ash and Aluminium Alloy (A-356.2), International Journal of Scientific and Engineering Research, Vol. 7, No. 3, 28-35

[37] Abdulwahab M., Dodo R.M., Suleiman I.Y., Gebi A.I., and Umar I. (2017). Wear behavior of Al-7\%Si$0.3 \% \mathrm{Mg} / \mathrm{Melon}$ Shell Ash Particulate Composites, Heliyon, Vol. 3, No. 8, e00375.

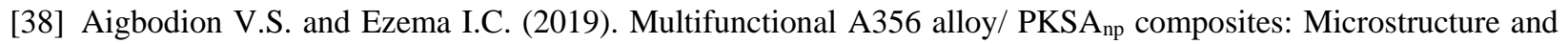
Mechanical Properties, Defence Technology, in press, https://doi.org/10.1016/j.dt.2019.05.017

[39] Ezema I. and Aigbodion V.S. (2020). Explicit Microstructural Evolution and Electrochemical Performance of Value Added Palm Kernel Shell Ash Nanoparticle/A356 Alloy Composite, Materials Science and Engineering Technology, Vol. 51, No. 3, 324-329.

[40] Satishkumar T., Shalini S., Krishnakumar K., Thavamania R. and Subramanian R. (2018). Bagasse Ash Reinforced A356 Alloy Composite: Synthesis And Characterization, Materials Today: Proceedings, Vol. 5, No. 2, Part 2, 7123-7130.

[41] Usman, Y., Dauda, E. T., Abdulwahab, M., and Dodo, R. M. (2020). Effect of Mechanical Properties and Wear Behaviour on Locust Bean Waste Ash (LBWA) Particle Reinforced Aluminium Alloy (A356 alloy) composites, FUDMA Journal of Sciences, Vol. 4, No. 1, 416 - 421.

[42] Nwafor S.C., Oke S.A. and Ayanladun C.A. (2020). Geometrical Parametric Optimisation of A356 Alloy Composite in a Two-Stage Casting Process for Automobile Wheel Covers Using Response Surface Methodology Parametric Optimisation of A356 Alloy Composite, Journal of Applied Science and Process Engineering, Vol. 7, No. 1, 457-478.

e-ISSN: 2289-7771 
[43] Gowda H. and Prasad P.R. (2016). Investigation of Mechanical Properties of $\mathrm{A} 356 / \mathrm{Al}_{2} \mathrm{O}_{3} / \mathrm{RHA}$ by Stir Casting Method, International Journal of Innovative Research and Development, Vol. 5, No. 11, 144-148

[44] Subrahmanyam A.P.S.V.R., Madhukiran J., Naresh G. and Madhusudhan S. (2016). Fabrication and Characterization of Al356.2, Rice Husk Ash and Fly Ash Reinforced Hybrid Metal Matrix Composite, International Journal of Advanced Science and Technology, Vol. 94, 49-56 